Please cite this article as:

Buganza T, Dell'Era C, Pellizzoni E, Trabucchi D and Verganti R (2015). Unveiling the Potentialities Provided by New Technologies: A Process to Pursue Technology Epiphanies in the Smartphone App Industry.

Creativity and Innovation Management, Vol. 24, No. 3, Pp. 391-414. (DOI: 10.1111/caim.12141) 


\section{UNVEILING THE POTENTIALITIES PROVIDED BY NEW TECHNOLOGIES: A PROCESS TO PURSUE TECHNOLOGY EPIPHANIES IN THE SMARTPHONE APP INDUSTRY}

[EIASM Limerick Special Issue, IPDMC 2014]

Tommaso BUGANZA

Department of Management, Economics and Industrial Engineering, Politecnico di Milano - Piazza L. da Vinci, 3220133 Milano Italy

Tel: +39 022399 2804, Fax: +39 0223992720

tommaso.buganza@polimi.it

Claudio DELL'ERA (corresponding author)

Department of Management, Economics and Industrial Engineering, Politecnico di Milano - Piazza L. da Vinci, 3220133 Milano Italy

Tel: +39 022399 2798, Fax: +39 0223992720

claudio.dellera@polimi.it

\section{Elena PELLIZZON}

Department of Management, Economics and Industrial Engineering, Politecnico di Milano - Piazza L. da Vinci, 3220133 Milano Italy Tel: +39 022399 3967, Fax: +390223992720

elena.pellizzoni@polimi.it

\section{Daniel TRABUCCHI}

Department of Management, Economics and Industrial Engineering, Politecnico di Milano - Piazza L. da Vinci, 3220133 Milano Italy

Tel: +39 022399 3967, Fax: +3902 23992720

daniel1.trabucchi@mail.polimi.it

\section{Roberto VERGANTI}

Department of Management, Economics and Industrial Engineering, Politecnico di Milano - Piazza L. da Vinci, 3220133 Milano Italy

Tel: +39 022399 2770, Fax: +39 0223992720

roberto.verganti@polimi.it

Keywords: Innovation of Meanings, Technology Epiphany, Smartphone App Industry

\section{Acknowledgements}

The authors would like to acknowledge all the practitioners who collaborated with us during the in-field data gathering process. Any mistakes or omissions are the sole responsibility of the authors. Financial support from the Lombardy Region fund "Dote Ricercatori e della Dote Ricerca Applicata per lo sviluppo del capitale umano nel sistema universitario lombardo" and the EU funded project "Light.Touch.Matters" are also gratefully acknowledged. 


\title{
UNVEILING THE POTENTIALITIES PROVIDED BY NEW TECHNOLOGIES: A PROCESS TO PURSUE TECHNOLOGY EPIPHANIES IN THE SMARTPHONE APP INDUSTRY
}

[EIASM Limerick Special Issue, IPDMC 2014]

\begin{abstract}
When new technologies approach the market, companies usually look for ways to improve existing applications or simply to replace previous technologies. The management literature identifies several strategies for gaining value from technological discontinuities: improving performance, becoming the cost leader, being the first-mover, managing the complementary assets and influencing regulations and standards. Scholars identified several managerial practices and processes to leverage all these strategies.

Recent literature suggests that there might be something more, namely, discovering new meanings, enabled by the technological discontinuity: a Technology Epiphany. This is still a young and largely unexplored research field, where, so far, no research has tried to understand what companies could do to actually develop such innovations.

This paper aims at identifying a process companies could adopt to pursue a Technology Epiphany strategy. Employing a case study approach, we investigated the navigation apps industry, both turn-by-turn and marine, to understand how companies manage the technology discontinuity embedded in smartphones. Comparing several players in the two industries, we first demonstrate that the rise of a new market leader is not related to a traditional strategy but to a Technology Epiphany. Finally, we propose a 5-step process to pursue a Technology Epiphany strategy: i) Unveil opportunities hidden in the technology; ii) Translate the opportunity into a New Meaning; iii) Develop new features to reveal the New Meaning; iv) Adapt the business model; v) Adapt the development process to the new environment.
\end{abstract}

\section{INTRODUCTION}

Sometimes companies fail in fully exploiting the opportunities provided by new technologies because they interpret them as means to replace previous technologies and improve already existing applications. As the semiologist Giampaolo Proni (2007) claims, "Technologies offer 
opportunities which are of course not infinite, but are greater in number than those imagined by early developers". Consequently, technological discontinuities can enable the development of completely different applications that address different needs in comparison to the previous generation.

In this vein, the recent and still embryonic literature about Technology Epiphanies suggests interesting insights about a new possible innovation strategy to obtain value from technological discontinuities (Verganti, 2009; Dell'Era et al., 2010). This strategy is primarily based on finding New Meanings inside existing technologies, changing the "why" people buy specific products and services rather than changing the "how" these products fulfil customer needs. In the early '80s, the Swiss wristwatch companies who were world leaders experienced a serious impact by the competition based on quartz movements and digital displays produced by Japanese and Hong Kong manufacturers. Interestingly, Swiss manufacturers were among the first companies to investigate the quartz technology, but they considered it not fitting their core competences in precision mechanics and assembly. On the contrary, their competitors were able to "see" in these new technologies the opportunity to revolutionize the market. In those years, digital displays were employed to communicate data in laboratory measurement devices, to display numbers in calculators and to create imaginary interactive worlds in futuristic handheld game devices by Nintendo (e.g., Donkey Kong). Thanks to quartz technology, LCD displays could be utilized in wristwatches, and companies such as Casio and Seiko began to produce multifunctional wrist-watches embedding lights, stopwatches, alarms, countdowns, calculators and even videogames. Thanks to these products, wristwatches shifted from being iconic, expensive status symbols with which to measure time to being inexpensive, fun, multifunctional electronic gadgets that are also able to measure time. This transformation changed the meaning of wristwatches as well as the reason why people wanted to buy them.

This exemplar case study demonstrates how companies often fail to consider new technologies as enablers for New Product Meanings. Technologies unveil numerous opportunities, particularly in the initial development stage. A multitude of these opportunities are indeed functional improvements of the already provided applications. Leveraging on knowledge created by R\&D activities and market analyses, companies previously saw only these opportunities and eventually replaced the technologies they utilized with the new ones to improve the current performance. The few existing research studies about Technology Epiphanies highlight that the discovery of other potential applications enabled by technological discontinuities requires envisioning New Meanings based on completely new 
performances and consequently, incomparable with the current applications. Going back to the previous example, Asian manufacturers did not interpret the quartz technology as a discontinuity enabling the improvement of the performance already provided by current watches (precision, lifetime, etc.), but as a discontinuity enabling the production of completely different applications and alternative performances (multi-functionality, flexibility, etc.).

Obviously, Technology Epiphanies are not the only way to obtain value from technological discontinuities. Many other strategies have been investigated so far (e.g., performance leadership, cost leadership or first-moving advantages). Thanks to the work of many researchers, our current knowledge about these strategies is significant. Normally, after the seminal works of some researchers who identify and describe the strategy (e.g., Porter, 1985; Murray, 1988), many other researchers focus on identifying what managerial practices are required to pursue it (e.g., Von Hippel 1986; Treacy and Wiersema, 1997; Lüthje and Herstatt, 2004). The interesting and pioneering literature about Technology Epiphanies is still in the first stage of this evolutionary path. It provides cases and examples useful to understand the phenomenon (e.g., Swatch, Nintendo Wii or iPod+iTunes) and describes the strategy companies could adopt to discover the quiescent meanings embedded in technological discontinuities (Verganti, 2009), but unfortunately, there is a lack of studies about how to pursue this innovation strategy. For this reason, the purpose of this paper is to identify a process companies could use to pursue a Technology Epiphany strategy.

The paper is organized as follows: in the next section, we highlight the most relevant literature contributions regarding innovation strategies enabled by technology, in the third section, we introduce the methodological aspects and illustrate the case studies analysed, in the fourth and the fifth sections, the case studies are presented, while the cross-case comparison is explored in the sixth section. The seventh section discusses the main results highlighting the managerial implications, and finally, the eighth section concludes the paper, providing limits and further research directions.

\section{CONCEPTUAL DEVELOPMENT}

In this section we firstly summarize the rich and consolidated literature streams about innovation strategies aimed at getting value from technological discontinuities; then we introduce the more recent literature stream about innovation of meanings where our 
conceptual framework is positioned and finally we highlight the lack of studies about its actual implementation.

\subsection{Innovation strategies aimed at getting value from technological discontinuities}

Abetti (1989) defines technology as 'a body of knowledge, tools and techniques, derived from both science and practical experience, which is used in the development, design, production and application of products, processes, systems and services'. The innovative potential embodied in each technology is widely accepted as a source of competitive advantage by academics, practitioners and governments. For this reason technological discontinuities are considered to be crucial game changer in terms of innovation. Scholars studied in depth technology cycles, defining technological discontinuity as the trigger periods of technological and competitive ferment that can change the innovation paths proposing a new dominant design (Tushman and Anderson, 1990). Firms can choose among several strategies aimed at getting value from technological discontinuities: performance leadership, cost leadership, first-mover strategy, complementary assets management, influence on regulations and standards.

In 1985 Porter identified different strategies to rule the market, creating the preconditions for several other researches aimed to cope with the five forces (Hill, 1988; Murray, 1988; Gopalakrishna and Subramanian, 2001). To gain the performance leadership is a first strategy to capture value from a technological discontinuity. The firm aims at being unique in its own industry, identifying some dimensions, valuable for buyers, and working on them in order to make its own product the best one on the market. Differentiation enables a premium price above-average thanks to the improved performances. A technology discontinuity can bring to leading-edge products with improved performances in comparison to the applications enabled by the previous technology (Rosenkopf and Nerkar, 1999; Cooper, 2005). Authors suggest several managerial practices to implement this strategy. Companies that want to follow this strategy should focus on the most updated technologies that lead to increase products performances or to carefully listen the market in order to identifying new valuable dimensions on which to compete. Technology intelligence literature suggests several methods to acquire and evaluate information on technological trends, such as roadmapping and experience curves (Porter et al., 1991; Martino, 1992; Kappel, 1998; Bucher, 2003). These recommended techniques are used not only for technology forecast but also to scout available technologies on the market, i.e. benchmarking studies (Ransley, 1996). Moreover several methods are proposed to listen to the users. Lead users analysis, for example, can be 
considered in order to understand new dimensions of performance (Von Hippel, 1986; Urban and Von Hippel, 1988; Lüthje and Herstatt, 2004). Finally, performance leadership can be implemented considering not only the product, but also the related services: enlarging the attractiveness of products with services may lead to superior performance perception (Vandermerwe and Rada, 1989; Treacy and Wiersema, 1997; Baines et al, 2007).

Porter (1985) identified a second strategy to rule the market: cost leadership. The technological discontinuity could lead a company to produce at the lowest cost within the industry. In this case, technologies impact on the production/delivery process enabling the cost reduction thanks to different drivers such as economies of scales, patents, preferential accesses etc. The product performances need to be considered as well: in order to make this strategy sustainable and gain above-average results buyers need to perceive the product comparable with the others. Treacy and Wiersema (1997) suggested that throughout operational excellence is possible to gain the best total cost and to reach an operational leadership, delivering the perfect match of quality, price and ease of purchase (e.g. McDonalds, Easy Jet) (McChrystal, 2014). Cost management techniques are developed in this vein (Cooper and Slagmulder, 1997). To reduce the cost of new products, managers can, for example, apply value engineering and target-costing approach (Monden, 1995; Seidenschwarz, 2003; Ibusuki and Kaminski, 2007).

Studying the relationship between technological discontinuities and market success many researchers focused on the moment when a company approaches the market: first-mover strategy. This is crucial because it could be a way to beat competitors; several scholars wrote about the so-called first-mover advantage (e.g. Kalyanaram, Robinson and Urban, 1955; Lieberman and Montgomery, 1988). The first firm that approaches the market can enjoy several advantages. Brand loyalty (e.g. Neidrich and Swain, 2003) represents a reputation advantage, because the firm has the chance to create a trust relationship with customers when no others competitors are approaching them. The first mover effect can also lead to patents that create strong entry barriers (e.g. Brigh, 1949; Bresnahan, 1985), preemption of scarce assets, in term of strategic location (e.g. Prescott and Visscher, 1977, Schmalensee, 1978; Rao and Rutenberg, 1979; Gilbert and Newbery, 1982), government concessions or exclusive access to input factors (e.g. Main, 1955). Moreover, if customers invest time and money in firm's product, they are unwilling to change it. Costs to switch to another product may represent another first mover advantage (e.g. Porter, 1976, 1980; Schmalensee, 1981; Wernerfelt, 1985). Finally, according to Spence (1981), if the industry is characterized by increasing returns, two more drivers have to be considered: the learning curve (e.g. 
Ghemawat, 1984; Shaw and Shaw, 1984) and the network externalities (facilitating a standard creation process). Several others scholars analyzed the timing effects (e.g. Robinson et al., 1992; Kalyanaram et al., 1995; Lee et al., 2000), underling empirically how these advantages are highly industry-related (e.g. Huff, 1982; Frederickson, 1984; Judge \& Miller, 1991; Vanderwerf \& Mahon, 1997). In order to be the first mover, it's necessary to reduce the time to market. A flexible approach, for example, can postpone the concept frozen of NPD projects (MacCormack et al, 2001; Buganza et al, 2010). Moreover standardizing interfaces between components in a product design can lead to an easy and quick introduction of the new technology in complex products leveraging on modularity and scalability (Sanchez and Mahoney, 1996; Baldwin and Clark, 2000; Worren et al, 2002).

Complementary assets management is another widely researched field to understand how to profit from technological discontinuities. Mitchell $(1989 ; 1992)$ proposes different categories of complementary assets: generic assets have multiple applications and can be easily contracted, whereas specialized and co-specialized assets are useful only in the context of a given innovation. Teece (1986) adopts a similar classification and proposes four main typologies of complementary assets: (i) competitive manufacturing; (ii) distribution; (iii) service; and (iv) complementary technologies. According to the incumbent's curse theory, innovations based on technological discontinuities are likely to be developed by new entrants (Tushman and Anderson, 1986) because they can exploit the advantage, due to a lack of commitment to the old technological regime. At the same time, established firms can leverage critical complementary assets to capture maximum value from new technologies (Teece, 1998; Tripsas 1997; Hill and Rothaermel, 2003). While this effect can be minimal if a technological change diminishes the value of these assets (Tripsass, 1997), it can be argued that established firms should perform no worse than newer ones, as long as they recognize the possibility of obsolescence for these assets. From a practitioners viewpoint Rothaermel (2001b) describes how established firms can cooperate to exploit the value of their complementary assets by adopting network strategies that are not available to new entrants, leveraging on strategic alliances, also with new entrants (Rothaermel, 2001a). A number of recent studies take a stance against the assumption that incumbents are cursed, and identify situations in which established firms actually have significant advantages in turbulent environments. Different key attributes have been identified, such as cultivating dynamic capabilities, possessing visionary leaders, working on absorptive capacity and adopting platform-based technologies with positive externalities showing how companies can actually leverage on complementary assets (e.g., Cohen and Levinthal, 1990; Tripsas and Gavetti, 2000; 
Hill and Rothaermel, 2003; Zahra and George, 2002; lansiti et al, 2003; MacCormack and lansiti, 2009; Buganza et al., 2009).

One last research field investigated to understand the linkages between technological discontinuities and market success is how to influence on regulations and standards. Laws and regulations can be fundamental in the emergence of a new technology (Miller et al, 1995; Islas, 1999), even in a pre-market phase (Valentine-Urbschat and Bernhart, 2008), the firm could enjoy an important competitive advantage betting on the right features that the lawmaker or the regulator will control. At the same time the ability to influence the standard setting process, both de facto and de jure according to the literature classification (Farrell and Saloner, 1988, 1992; David and Greenstein, 1990; Besen and Farreell, 1994), can be extremely useful in order to extract value from a breakthrough technology, reaching a dominant position on the market. Scholars identified different organizational models that can lead to influence on regulations and standards. For example, organizing consortia help industries in the standards development process (Weiss and Cargill, 1992). These groups of company, sharing some special interests in a technological development, can create industry lobbies, able to influence policy makers and government choices (Grossman and Helpman, 1992; Damania and Fredriksson, 2000). Literature on company collaboration provides several examples of organizational models that can be used to follow this strategy (Chiesa and Manzini, 1998; Guan and Zhao, 2013). Moreover, standards can rise thanks to close collaboration with universities (Guan and Zhao, 2013).

\subsection{The role of innovation of meanings in getting value from technological discontinuities}

Performance leadership, cost leadership, first-mover strategy, complementary assets management and influence on regulations and standards are among the most recognized and studied strategies to profit from technological discontinuities. More recently another possible strategy arose. According to Verganti (2009) each technology embeds a set of disruptive new meanings that are waiting to be uncovered. If a company reveals those quiescent meanings, it will seize the technology's full value, celebrating what Verganti (2009) calls a technology epiphany. In fact "Epiphany" etymologically means "a manifestation that stands in a superior position; a perception of the essential nature or meaning of something" (Merriam-Webster Dictionary).

According to established theories of innovation management, design can act as a differentiator in mature industries (Abernathy and Utterback, 1978; Foster, 1986; Tushman and Anderson, 1990; 2004; Utterback, 1994; Christensen, 1997; Christensen and Rosenbloom, 
1995): every industry is characterized by 'technological discontinuities' that, emerging at irregular time intervals, force companies to significantly innovate regarding their technological paradigms: '[these discontinuities] are based on new technologies whose technical limits are inherently greater than those of the previous dominant technology, along economically relevant dimensions of merit' (Tushman and Anderson, 2004). More precisely, one or more radically new technologies break into an industry opening a ferment era; this stage allows leapfrog changes of functions and performance. In this stage, competitors struggle to find the most effective product architecture, and solve technological problems. When the technology has run its course, innovation becomes incremental, the product innovation speed decreases, and everyone waits for another technological discontinuity. At this stage, design starts playing a role as a differentiator during incremental innovations by making products different from competitors' by leveraging on creativity, user interface and style.

Recent literature about technology epiphanies (Verganti, 2009; Verganti, 2011a; Verganti, 2011b; Norman and Verganti, 2014; Simoni et al., 2014) questions this ancillary role of design and shows how design can play a major role in a technology's inception as well, particularly when a technology discontinuity arises. When a technology discontinuity emerges, it embeds many potential meanings. Some are immediate and promoted by those who have initially guided technological development. Other meanings are quiescent, but sooner or later they become manifest (see Figure 1). 


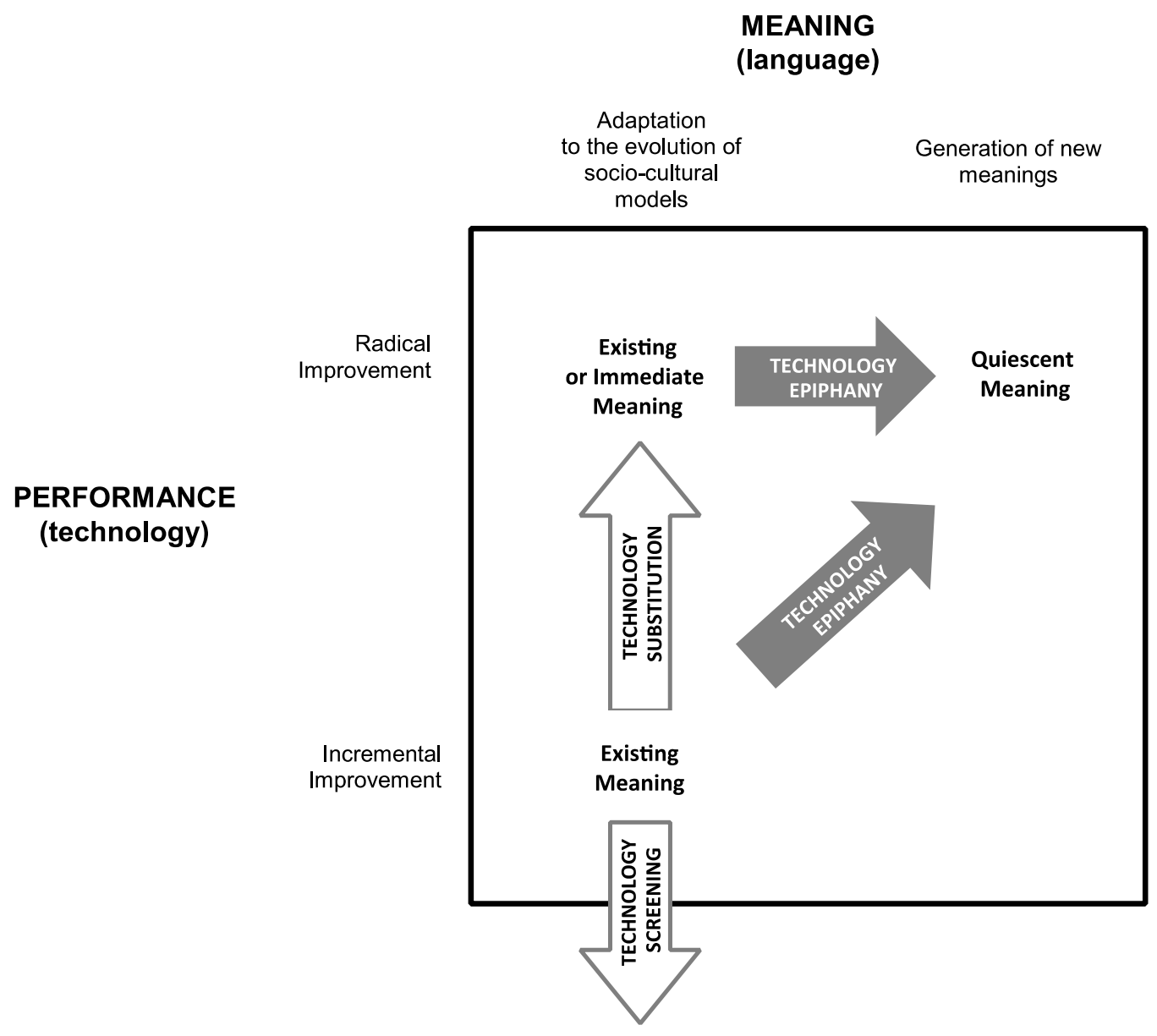

Figure 1: Conceptual framework: technology screening, substitution and epiphany

(Verganti, 2009)

Shortsighted companies often focus on searching new markets for a technology without taking into consideration the potential new meanings of the technology itself. In this way, when companies look for potential applications, they focus solely on technological substitutions. In these cases companies add more effective and powerful functionalities or improve performances, leaving the existing meaning untouched. This approach leads to two myopic behaviors. On the one hand, if the most immediate meaning of a new technology cannot support the meaning existing in the market, companies screen it off, considering it irrelevant. On the other hand, if the most immediate meaning of the new technology does fit the existing meaning, a company will invest by substituting the current technology with the new one. However, someone will eventually have a technology epiphany (Verganti, 2009). A technology epiphany may occur when a company has understood that a radical new meaning can emerge in the market and therefore is open to new technologies - usually those that competitors have screened off. Alternatively, a technological epiphany may occur when a 
company searches for the more-powerful meanings that a new technology embeds, as indicated by the horizontal arrow (see Figure 1). The same phenomena were also recognized by Tempelman et al. (2012) when they spoke of the need for 'technology transformation' i.e., the process of change that a technology undergoes when it gets 'productized' during product design.

The Nintendo Wii represents an exemplar case study that allows to better understand the concept of technology epiphany. With the launch of the Sony PlayStation (1995), the PlayStation 2 (2000), and the Microsoft Xbox (2001), Nintendo lost its leadership and fell on hard times. Microsoft and Sony pushed even harder with their later consoles, the Xbox 360 (May 2005) and the PlayStation 3 (November 2006). Both consoles were more powerful than their predecessors, offering high-definition images and more-complex games and graphics. Nintendo's positioning was very weak in comparison to Microsoft and Sony, its products seemed to be not able to compete in terms of complexity and performances. Probably for this reason Nintendo decided to play a completely different game. They developed the Wii, a radically new console characterized by having motion-sensitive controllers. These controllers leveraged a breakthrough technology: MEMS (Micro-Electro-Mechanical Systems) accelerometers, developed by STMicroelectronics. Surprisingly, Sony was already adopting the same technology in other product categories, and Microsoft was the first company to get in touch with a prototypical console developed by STMicroelectronics. Nevertheless they did not see how this technology could improve the high definition graphic and game complexity even more and screened the technology off. In the first two months after its release, the Wii sold 1 million units. In April 2007, six months after its release, the Wii's sales in the U.S. market were twice those of the Xbox 360 and four times those of the PlayStation 3. What Nintendo did with Wii was not just to bring a new technology into the industry. Nintendo radically changed what a console game means to the user. Unlike the competitors, Wii games were simple in graphic, not 3D accelerated, easy to play and require short time for a match. They were typically multiplayers game but players were in the same room, interacting in the real world like in board games and not through the internet. More than being the technological evolution of previous consoles, the Nintendo Wii is the Monopoly ${ }^{\circledR}$ game of our century.

As previously mentioned, the literature about consolidated strategies aimed at getting value from technological discontinuities not only provides clear indications about strategic approaches, but suggests also associated managerial practices (see Table 1). On the contrary technology epiphanies are still a largely unexplored research field. The phenomenon was 
identified and described, but, to the best of our knowledge, no research tried so far to shed some light on how to actually develop such innovations. More precisely, the literature about technology epiphanies describes the strategy companies can adopt in order to discover the quiescent meanings embedded in technological discontinuities, but no research evidences have been collected about what concrete actions should be put in place in order to pursue this peculiar strategy (see Table 1). According to Alvesson and Sandberg (2013) this is a typical application gap in the current body of knowledge and this article aims at starting to bridge it. 


\begin{tabular}{|c|c|c|c|}
\hline Strategy & References & $\begin{array}{l}\text { Practices to pursue the strategy } \\
\text { (process, tool, etc.) }\end{array}$ & References \\
\hline PERFORMANCE LEADERSHIP & Porter, 1985; Murray, 1988 & $\begin{array}{l}\text { Technology intelligence methods: } \\
\text { - } \quad \text { Road-mapping Experience curves } \\
\text { - } \quad \text { Benchmarking studies } \\
\text { - } \quad \text { Lead users analysis } \\
\text { - } \quad \begin{array}{l}\text { Products Services System integration/ } \\
\quad \text { Servitization }\end{array}\end{array}$ & $\begin{array}{l}\text { Von Hippel, 1986; Urban and Von Hippel, 1988; } \\
\text { Vandermerwe and Rada, 1989; Porter et al., 1991; } \\
\text { Martino, 1992; Ransley, 1996; Treacy and } \\
\text { Wiersema, 1997; Kappel, 1998; Bucher, 2003; } \\
\text { Lüthje and Herstatt, 2004; Baines et al, } 2007\end{array}$ \\
\hline COST LEADERSHIP & Porter, 1985 & $\begin{array}{l}\text { Cost management techniques: } \\
\text { - } \quad \text { Value engineering } \\
\text { Target-costing approach }\end{array}$ & $\begin{array}{l}\text { Monden, 1995; Treacy and Wiersema 1997; } \\
\text { Cooper and Slagmulder, 1997; Seidenschwarz, } \\
\text { 2003; Ibusuki and Kaminski, 2007; McChrystal, } \\
2014\end{array}$ \\
\hline FIRST-MOVER STRATEGY & $\begin{array}{l}\text { Kalyanaram, Robinson and Urban, 1955; } \\
\text { Lieberman and Montgomery, } 1988\end{array}$ & $\begin{array}{ll}\text { - } & \text { Patenting } \\
\text { - } & \text { Preemption of scarce assets } \\
\text { - } & \text { Switch costs and lock-in effects } \\
\text { - } & \text { Flexible process } \\
\text { - } & \text { Scalability and modularity } \\
\end{array}$ & $\begin{array}{l}\text { Sanchez and Mahoney, 1996; Baldwin and Clark, } \\
\text { 2000; MacCormack et al, 2001; Worren et al., } \\
\text { 2002, Buganza et al., } 2010\end{array}$ \\
\hline COMPLEMENTARY ASSET MANAGEMENT & Teece, 1986; Teece, 1998 & $\begin{array}{ll}- & \text { Network strategies } \\
- & \text { Appropriation and absorptive capacity }\end{array}$ & $\begin{array}{l}\text { Cohen and Levinthal; 1990; Tripsas and Gavetti, } \\
\text { 2000; Rothaermel, 2001a; Rothaermel, 2001b; } \\
\text { Zahra, and Gerard, 2002; Rothaermel and Hill, } \\
\text { 2003; lansiti et al, 2003; Buganza et al, 2009; } \\
\text { MacCormack and lansiti, 2009 }\end{array}$ \\
\hline INFLUENCING REGULATIONS AND STANDARDS & $\begin{array}{l}\text { Farrell and Saloner, 1988, 1992; David and } \\
\text { Greenstein, 1990; Besen and Farreell, } 1994\end{array}$ & $\begin{array}{ll}\text { - } & \text { Consortia } \\
\text { - } & \text { Lobbies } \\
\text { - } & \text { Collaboration with companies } \\
\text { - } & \text { Collaboration with universities } \\
\end{array}$ & $\begin{array}{l}\text { Grossman and Helpman, 1992; Weiss and Cargill, } \\
\text { 1992; Chiesa and Manzini, 1998; Damania and } \\
\text { Fredriksson, 2000; Guan and Zhao, } 2013\end{array}$ \\
\hline TECHNOLOGY EPIPHANY & Verganti, 2009 & \multicolumn{2}{|c|}{ Literature Gap } \\
\hline
\end{tabular}




\section{RESEARCH DESIGN}

\subsection{Research methodology}

As previously mentioned the purpose of this paper is to identify a process companies could use to pursue a technology epiphany strategy. Due to lack of previous studies the research is exploratory in nature, hence we adopted a case study methodology approach, which allows to develop an holistic and contextualized analysis and to identify the critical variables of a phenomenon (Eisenhardt and Graebner, 2007). The case study analysis answers to "how" and "why" questions (Yin, 2003). Therefore, it fits our purpose to understand how company can actually implement a technology epiphany strategy. Our case studies have an exploratory intent, are retrospective and multiple in nature and, finally, rely on secondary resources (Yin, 1984).

\subsection{Empirical setting}

The Smartphone Applications industry represents an intriguing empirical setting to explore this research objective, for several reasons. As stated by the report 'The Mobile Consumer - A Global Snapshot' developed by Nielsen in 2013, 'when the first call was placed on a handheld mobile phone in 1973, the prototype device used was capable of less than 30 minutes of battery life and took 10 hours to re-charge. Fast-forward some 40 years later and mobile device ownership has reached critical mass around the world. Today, these devices serve as the primary communications and media vehicles for many and play an increasingly important role in the daily lives of consumers in both developed and high-growth economies'. According to the report 'Big Data: The next frontier for innovation, competition and productivity' developed by the McKinsey Global Institute in 2011, more than 5 billion mobile phones were in use in 2010, and this trend is still growing. By the end of 2013, global smartphone penetration had exploded to $22 \%$ of the global population, from $5 \%$ in 2009 . That is an increase of nearly 1.3 billion smartphones in four years.

In addition to its economic and social relevance, the smartphones application industry represents a major opportunity to study technology epiphanies. One of the main challenges for this research is to define the sample for the empirical research finding actual cases of technological epiphanies. Thus it's necessary to find companies that after a major technological breakthrough, succeeded leveraging on technology epiphany strategy and not thanks to one or more of the other possible strategies presented in the literature review: i) 
performance leadership, ii) cost leadership, iii) first-mover strategy, iv) complementary assets management and v) influence on regulations and standards. Choosing the smartphone app industry allows waving two of these strategies: complementary assets management and influence on regulations and standards (the remaining three strategies will be proved to be not significant in the two cases studies analyzed and compared within this industry).

In the smartphone App industry all players share the same complementary assets (Teece, 1986) and consequently they are invariant among different players.

\section{- Distribution}

App distribution is managed by the marketplaces (App Store and Google Play), which handle and distribute each App in the same way.

- Complementary technologies

Players in this industry share the same complementary technologies because all the Apps run on the same devices. Every App developer can leverage cameras, GPS antennas, compasses, Bluetooth etc. because these sensors are embedded in the device and accessible to every developer.

- Services

As with distribution, the marketplaces, which provide storage, manage the large majority of the relevant services in this industry centrally payment management, downloads, reviews, and ratings, in the same way for all players.

- Competitive manufacturing

In this software-based and virtual industry, these complementary assets are not relevant.

Also in terms of influence on regulations and standards the smartphone App industry doesn't allow major differences among players. Rules are the same for each app in the category and standards related with contents, publication processes, technical aspects etc. are managed by marketplace owners and hardly influenced even by major players.

Thanks to these characteristics, this industry allows us to focus our analysis on few of the strategies mentioned in the literature review: performance leadership, cost leadership, firstmover strategy and, obviously, Technology Epiphanies.

\subsection{Case studies selection}

The smartphone App industry includes many different categories like games, finance, business etc. (currently the Apple App Store lists 24 categories). In order to achieve in depth knowledge and analysis we focused on a single one (Navigation) and we selected two case studies: Turn- 
by-Turn Navigation Applications and Marine Navigation Applications. The choice was made by looking for categories with clear market leaders, elevated number of players and recognized existing incumbents/meanings before the technological breakthrough. Moreover the navigation industry has been recently transformed by the new opportunities provided by a technological discontinuity: smartphone technologies. According to the McKinsey Global Institute (2011), 'the use of real-time traffic information to inform navigation will create a quantifiable consumer surplus through savings on the time spent travelling and on fuel consumption. Mobile location-enabled applications will create surplus from consumers, too. In both cases, the surplus these innovations create is likely to far exceed the revenue generated by service providers ( $\$ 100$ billion+ revenue for service providers, Up to $\$ 700$ billon value to users)'.

\subsection{Data analysis}

The case studies leveraged on secondary data retrieved throughout different sources: app stores (American Apple App Store and Google Play for general information, number of reviews, average rating and number of recommendations), official Facebook page of the app (number of likes), official website of the app (general information) and AppAnnie (release date). All data have been retrieved on April 3, 2014. In each industry, the success of the apps was outlined leveraging on users' opinions. In order to understand the popularity of the apps the following data have been analyzed: number of recommendation on Google, likes on Facebook, reviews on app stores and average rating (stars) on App Stores. Then, we analyzed the cases using the same framework:

- Competitive Context: both case studies start from the existence of market leaders before the technological discontinuity and from the evidence of the presence of current market leaders able to leverage the opportunities provided by smartphone technologies. Moreover, we prove in this section that none of the standard strategies to getting value from a technological discontinuity (performance leadership, cost leadership and first-mover strategy) can explain the current market structure;

- Technology Epiphany: analyzing the applications that leverage smartphone opportunities, we explore and interpret their meaning; in other words, we differentiate those applications that show the same meaning supported by old applications from those able to propose new meanings. 
- Implementation Actions: analyzing the applications that leverage smartphone opportunities, we analyze the implementation actions adopted by each of them in order to succeed.

Thanks to this framework, we can compare the cases extrapolating the process they followed to implement a technology epiphany strategy.

\section{CASE 1: TURN-BY-TURN NAVIGATION APPLICATIONS}

\subsection{Competitive Context}

Since the late '90s when GPS systems were first launched, the market has been dominated by Navigation Portable Devices (NPD). The market was practically a duopoly, with a market leader in USA (Garmin) and one in Europe (TomTom). Both of these companies are experiencing a dramatic drop in device sales. Garmin expects revenue from its personal navigation device unit to fall 10-15 percent in $2014^{1}$. Similarly, TomTom's forecast adjusted earnings per share in 2014 down 23 percent from 2013, reaching its lowest level since its stock market listing in $2005^{2}$. Navigation Portable Devices are being substituted with Apps running on smartphones. In 2013, for the first time, the number of active navigation App users overcame the installed base of NPDs. Forecasts says that the ratio in 2017 will be $4: 1^{3}$.

This strong trend clearly shows that even if in the beginning users of NPDs and users of smartphone apps were possibly different in terms of navigation service needs (professional, reliable high frequency use for NPDs against more occasional use for smartphone apps), now this distinction is less and less true. Not surprisingly, indeed, Apple developed and launched in 2014 (in partnership with the main car manufacturers) the new Apple CarPlay service to fully integrate the iPhone in the car and replace the NPDs and OEM mapping services. Even if the two former market leaders entered the new App market quite soon and lowered the price of their offering (considering that they did not sell the device anymore), they lost their predominance anyway. When Google's free map and navigation App became available for iPhones in December 2012, 10 million people downloaded it in just two days; Garmin sells almost the same amount of GPS devices in one year ${ }^{4}$.

After the technological discontinuity, new market leaders appear to be Waze and Google Maps. Looking at Figure 2 (where the most popular apps in the market are compared), the

\footnotetext{
${ }^{1}$ http://www.reuters.com/article/2014/02/19/garmin-results-idUSL3NOLO38R20140219

2 http://www.reuters.com/article/2014/02/11/us-tomtom-resultsidUSBREA1AOBJ20140211

${ }^{3}$ http://www.berginsight.com/ReportPDF/ProductSheet/bi-mns6-ps.pdf

${ }^{4}$ http://www.technologyreview.com/news/511786/a-shrinking-garmin-navigates-the-smartphone-storm/
} 
two apps lead the market in term of recommendations on Google Play, likes on Facebook, reviews on app stores and average rating (stars) on App Store. Google will not further been considered in the analysis because it is not a pure turn-by-turn navigation app and also because Google bought and integrated Waze back in 2013. We will focus on Waze instead, which is a pure navigation App, hence easier to be compared with other Apps and NPDs. Moreover, it represents an astonishing success case, as it was based on a community of 50+ million users in 2013 when Google decided to buy it for $\$ 1+$ billion.

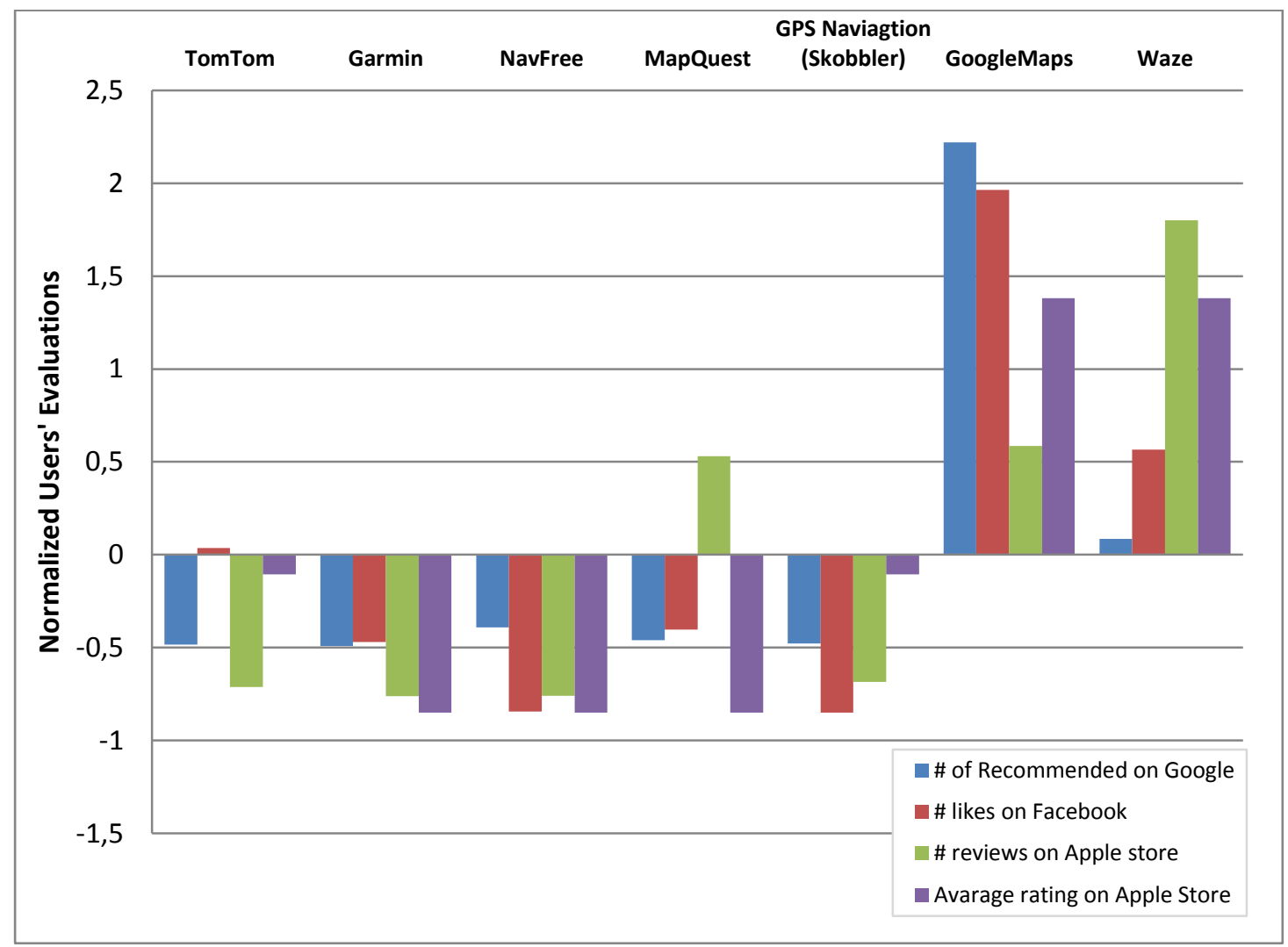

Figure 2: Users' evaluations of Turn-by-Turn Navigation Apps ${ }^{5}$

Many new entrants approached the market after the technology discontinuity, leveraging on different strategies. As mentioned in the previous section, two strategies (managing complementary assets and influencing regulations and standards) cannot be considered in this field, because they are invariant among all the players. Table 2 compares the sample along the remaining strategies.

\footnotetext{
${ }^{5}$ \# of like on Facebook: if both the company and the specific app have a Facebook page we took the one with more likes, with the exception of Google Maps, where Google general page would have been highly influenced by other factors; Reviews on app stores: when the same app is both on Apple App Store and Google Play Store we picked the one with more reviews.
} 


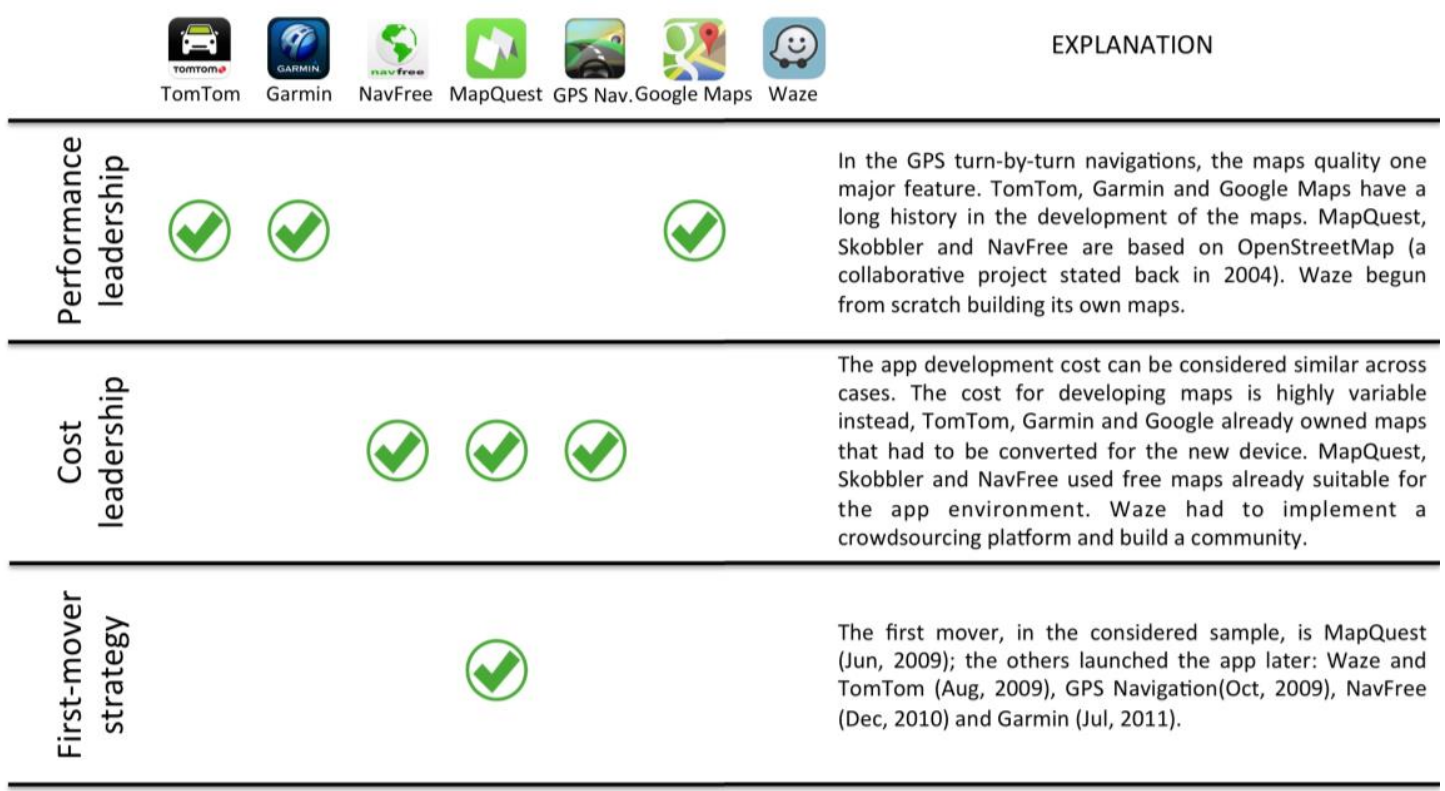

Table 2: Strategies in Turn-by-Turn apps

According to Table 2 both incumbents (TomTom and Garmin) and some new entrants (NavFree, MapQuest, GPS Navigation) successfully implemented at least one strategy. Waze instead seems to not leverage on any of competitive drivers analyzed ${ }^{6}$. As a result none of the major strategies to getting value from new technologies seems to be able to explain the success of Waze against the competitors. The reason for Waze success has to be searched somewhere else: the new meaning proposed.

\subsection{Technology Epiphany: Waze}

Building on the work of Verganti (2009), we claim that the shift from Navigation Personal Devices to Navigation Apps on smartphones is mainly a technology substitution (see Figure 3). In addition to changing the device and adapting the technology, no breakthrough innovation was introduced. Nearly all the turn-by-turn Navigation Apps offered the same functions: i) driving you from one place to another following the best route according to specific limitations (no tolls, panoramic); and ii) calculating your ETA (expected time of arrival).

$6 \mathrm{It}$ is important to underline that Google Maps is not considered along the first-mover strategy, because their maps were used in a pre-installed app in the first five major iOS releases and initially it did not have a navigation feature. 


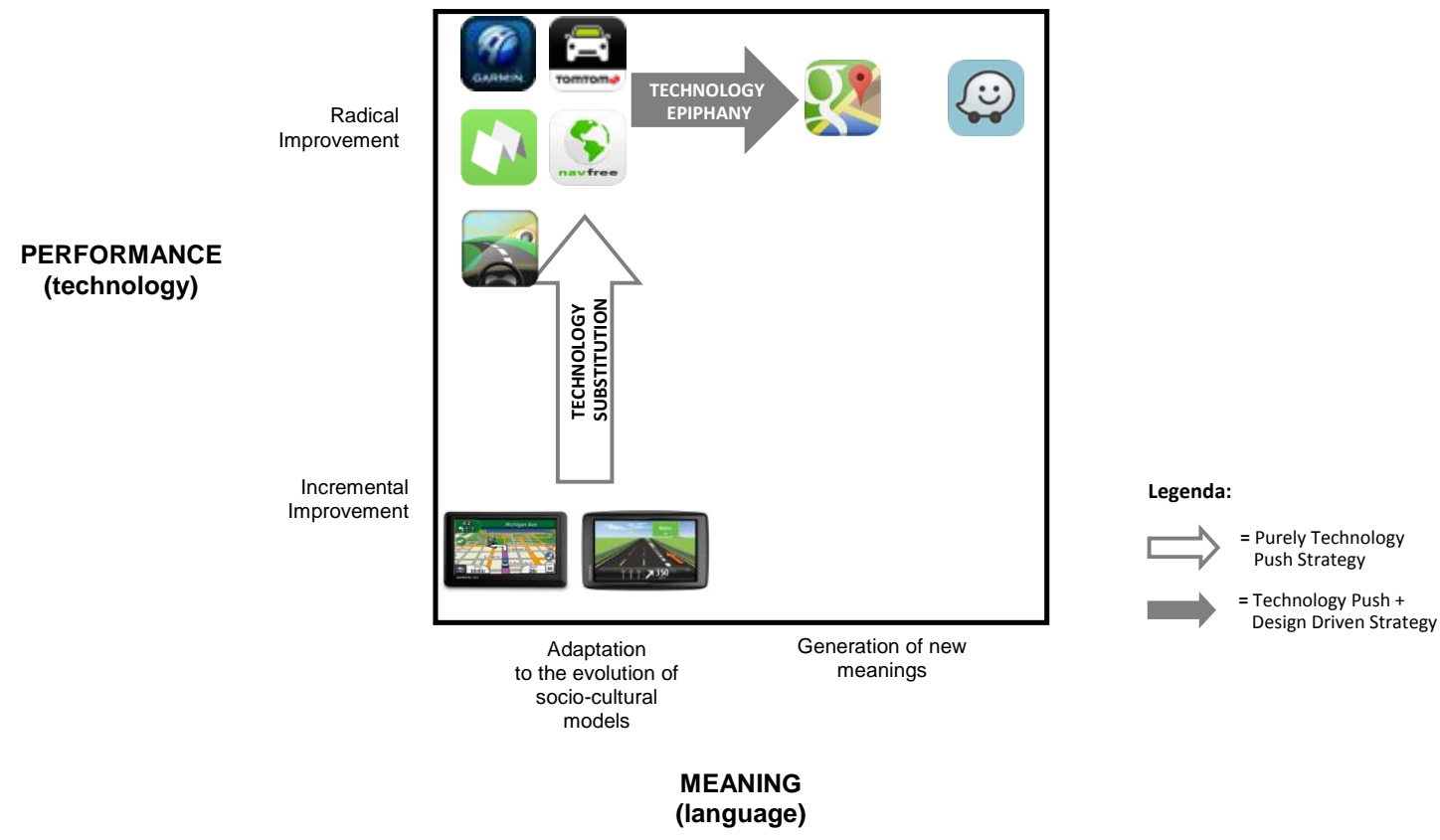

Figure 3: Technology Substitution and Technology Epiphany in Turn-by-Turn Navigation Industry

One remarkable exception is Waze, which was able to generate a real, new meaning for the industry. Waze is a company founded in 2008. The business idea was based on the creation of new maps thanks to the users; later, it changed into the current GPS-turn-by-turn navigator with a massive social component.

"Get the best route, every day, with real-time help from other drivers."

(www.waze.com)

Waze changed "why" people use a navigation service more than changing "how" they use it. Since the beginning of the industry, the main meaning of turn-by-turn navigation has been unchanged: to drive users from one place to another when they did not know the route. This meaning was the same for Navigation Personal Devices and for all the Navigation Apps we reviewed (TomTom, Garmin, NavFree, MapQuest, and Skobbler). This means that we do not use navigation while driving on a known route, which is probably the large majority of the time we spend driving. Waze completely changed this meaning. It was designed to be used also when we know exactly where to go. The traffic feature is a good example of this. Traffic conditions may affect the best route to travel to a familiar place. Waze is designed to collect information from all the wazers and to use them to adapt the route in real-time according to 
the traffic conditions. The application is completely built on the concept of being useful for every drive. To achieve this new meaning, Waze did not leverage any particularly innovative technology. The whole technological environment provided by smartphones is the same for competitors. Still, Waze was able to unveil some 'hidden' opportunities already existing in those technologies.

\subsection{Implementation actions}

In order to make the new meaning actual, Waze had to implement different actions. First of all they developed a community and a whole set of new community based features to declare and reveal the new meaning to the customers: by-pass traffic, real time road alerts, and best gas prices. Waze is able to extract as much value as possible from the community because it has designed an effective collaboration process which allows everyone to contribute according to their will and their sense of belonging to the community.

Let us consider, for example, Waze's maps and traffic services. Every Wazer is contributing to them simply by turning the application on and driving. GPS data will tell the company when new roads are created or when Wazers are stuck in a traffic jam. A second level of collaboration is more active, as Wazers can report road closings, works, car crashes, and police patrols by clicking on the App (the entry will be automatically geolocalized). This information will be used both to update the maps and to change the routes of upcoming Wazers to help them avoid the same traffic jams. Finally, the community can also decide to actively work on maps by changing them or accepting/refusing changes proposed by other members (the contribution process prevents hazardous behaviors, letting the user change only those routes he/she drove through).

After introducing these features, which dramatically expanded the usage of the navigator, making it useful even when driving on known routes, Waze leveraged the community concept even more by introducing more personalized social functions: 'driving is not just for getting yourself for one point to another; much of the time you spend on the road you are on the way to meet up with friends, pick up family or doing co-workers"7. For example, they now provide services to' receive pick-up requests from friends. Waze will drive you to the pick-up place and provide your friends with your live-updated ETA to be sure you meet at the right time. It is relevant to note that all these features imply to be continuously connected to Waze servers. Thus, users who don't have good data reception in areas that they usually drive in, or who just don't want to surpass their limited data plan quota might perceive a trade-off between these

\footnotetext{
${ }^{7}$ www.youtube.com/watch?v=1KCYEMkpZ1k
} 
aspects and the benefits offered by Waze. Nevertheless, 50+ million Wazers appear to be happy to contribute to the community, as they see the results of their (small) efforts. In other words, Waze was able to find the community and the community's dynamics within the smartphone technology.

In order to pursue the technology epiphany strategy Waze had to modify the dominant business model in turn-by-turn navigation industry. Nearly all companies selling Navigation Personal Devices used to share the same business model: provision of both the hardware (GPS antenna, screen, speaker...) and the maps (including the updating service). Smartphones significantly changed this competitive environment, as the hardware is now designed and sold by third parties (mobile manufacturers). Companies such as TomTom and Garmin, as well as new entrant Apps providers (MapQuest, NavFree), approached this new environment with a similar business model, selling the applications in the App stores (e.g., Apple Store and Google Play) and/or using the in-App purchases to provide users with premium services or updated maps. Waze approached the market with a completely different business model: the App is available for free. The value of the App is related to the network externality (the bigger the community, the better the service) and is embedded in the continuous improvement of the maps. Using the typical business model for App providers, the income flows are related to advertising8. Instead of polluting the application with banners, though, Waze provides the opportunity to buy location based ads inside the maps, publicizing businesses when customers are near to the point of sale (e.g. when they are stopped at a nearby traffic light). Users perceive this non-invasive marketing strategy as a service.

Finally, in terms of development processes, the technological switch from stand-alone devices to smartphones dramatically impacted the market. The NPDs' traditional business was based on an approximately one-year product lifecycle. The main market players still update their maps quarterly. The smartphone App market is completely different. Speed is one of the most important competitive factors. Waze maps are updated daily and both Waze and Google Maps do not store whole maps on the phone but always enable the download of portions of a map from the internet when needed. In this way, a map update is delivered on the next download. Speed is not solely a matter of content, however. NPDs were launched on the market on a yearly basis, and main innovations were embedded into them with the same frequency. Smartphone applications have a much faster release frequency. It is interesting to note that the Apps by TomTom and Garmin show no relevant differences regarding the innovation speed when compared with native smartphones applications. In Figure 4, it is possible to

${ }^{8}$ https://biz.world.waze.com 
appreciate these similarities by looking at the average frequency of releases since each application's first publication (data regarding dates and contents of each single release have been retrieved from Apple App Store and AppAnnie on April 3, 2014). To allow a deeper analysis, we first compared the general release frequency (any release is counted), and then we eliminated the releases that included only bug fixing and divided the remaining releases into improvement releases (e.g., improvement of existing features) and main improvement releases (e.g., complete new features or App redesign). Four researchers did independently the release coding by classifying every release along the app history, then data have been compared and averaged. No major differences are detectable among different players. Garmin appears to be considerably faster than others, but we must also report that no main improvements have been introduced since Q4 2012.

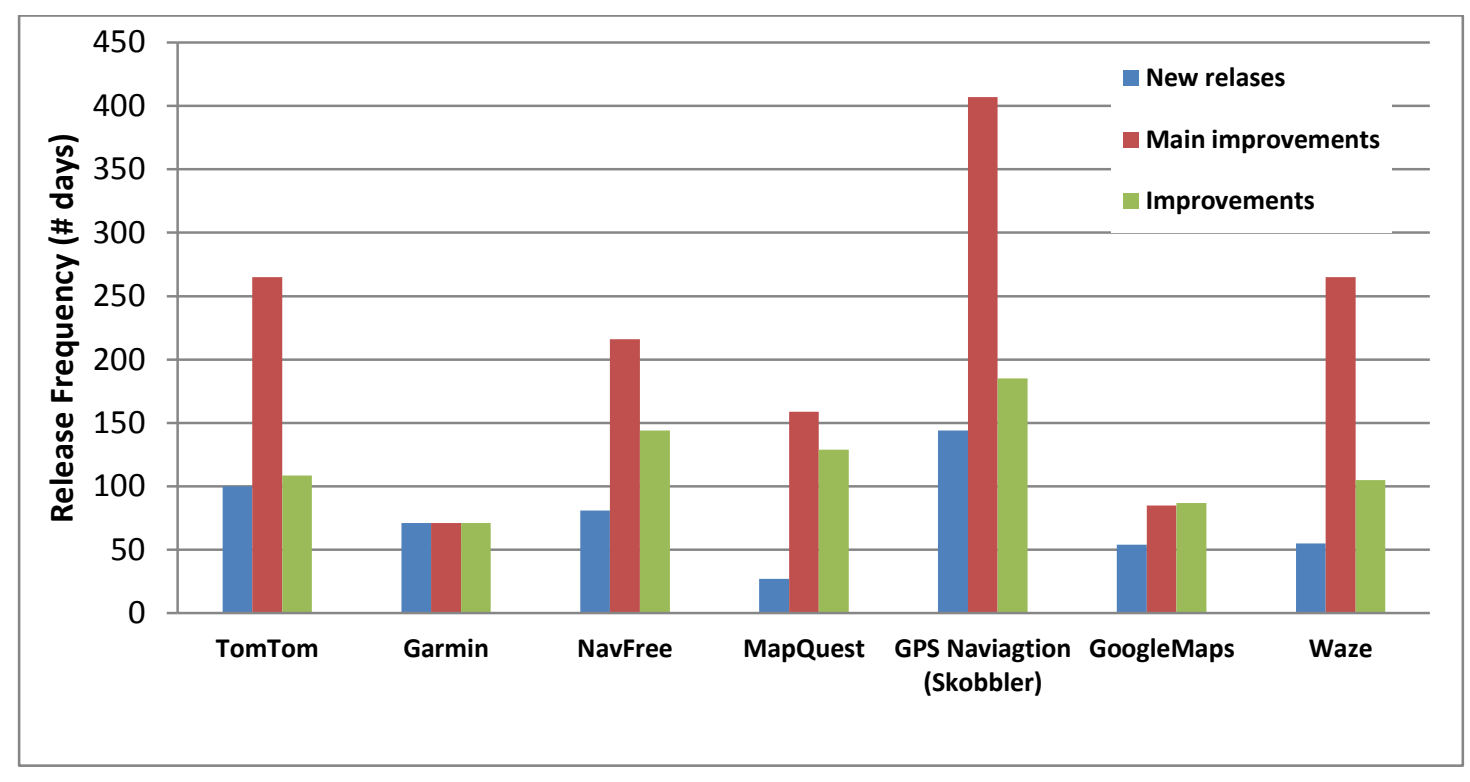

Figure 4: Release Frequency for Turn-by-Turn Navigation Apps

Finally, we can say that in order to implement the new meaning and get full advantage from the technology epiphany strategy Waze had to i) develop a full set of features leveraging on the community, ii) challenge and adapt the dominant business model in the industry and iii) challenge and adapt the dominant development processes and practices in the industry.

\section{CASE 2: MARINE NAVIGATION APPLICATIONS}

\subsection{Competitive Context}


The market started at the end of the '80s with companies such as Garmin, Raymarine, and Navman integrating GPS sensors into their chart plotters. Since the early stages of the industry, the dominant business model was based on the separation between hardware and content providers. On one hand, companies such as Raymarine, Navman, Lowrance, and Hummingbird design and manufacture the chart-plotters. On the other hand, companies such as Navionics and C-Map (now Jeppesen, a Boeing company) produce digital maritime cartographies that can be mounted on different devices. Garmin represented an exception to this model as its devices used proprietary charts for a long time. Unlike the turn-by-turn navigation industry, the marine navigation industry has not been completely revolutionized yet by the new smartphone/tablet technology. Chart-plotter manufacturers continue to lead the market, probably because their devices have a more reliable GPS fixing and are integrated with many other boat safety-critical devices such as sonars and radars. Nonetheless, the technological breakthrough has started. iNavx proposed the first marine navigation app (Aug, 2008), then several new entrants (Charts\&Tides, Marine Navigation Lite, SeaNav, Openseamap) and incumbents charts provider (Navionics, Jeppesen and Garmin) proposed their apps as well.

Looking at Figure 5 (where the most popular apps in the market are compared) iNavx leads the market in term of reviews on the Apple store, but its average rating is similar to others. Considering the entire set of indicators, Navionics seems to be widely the most appreciated. 


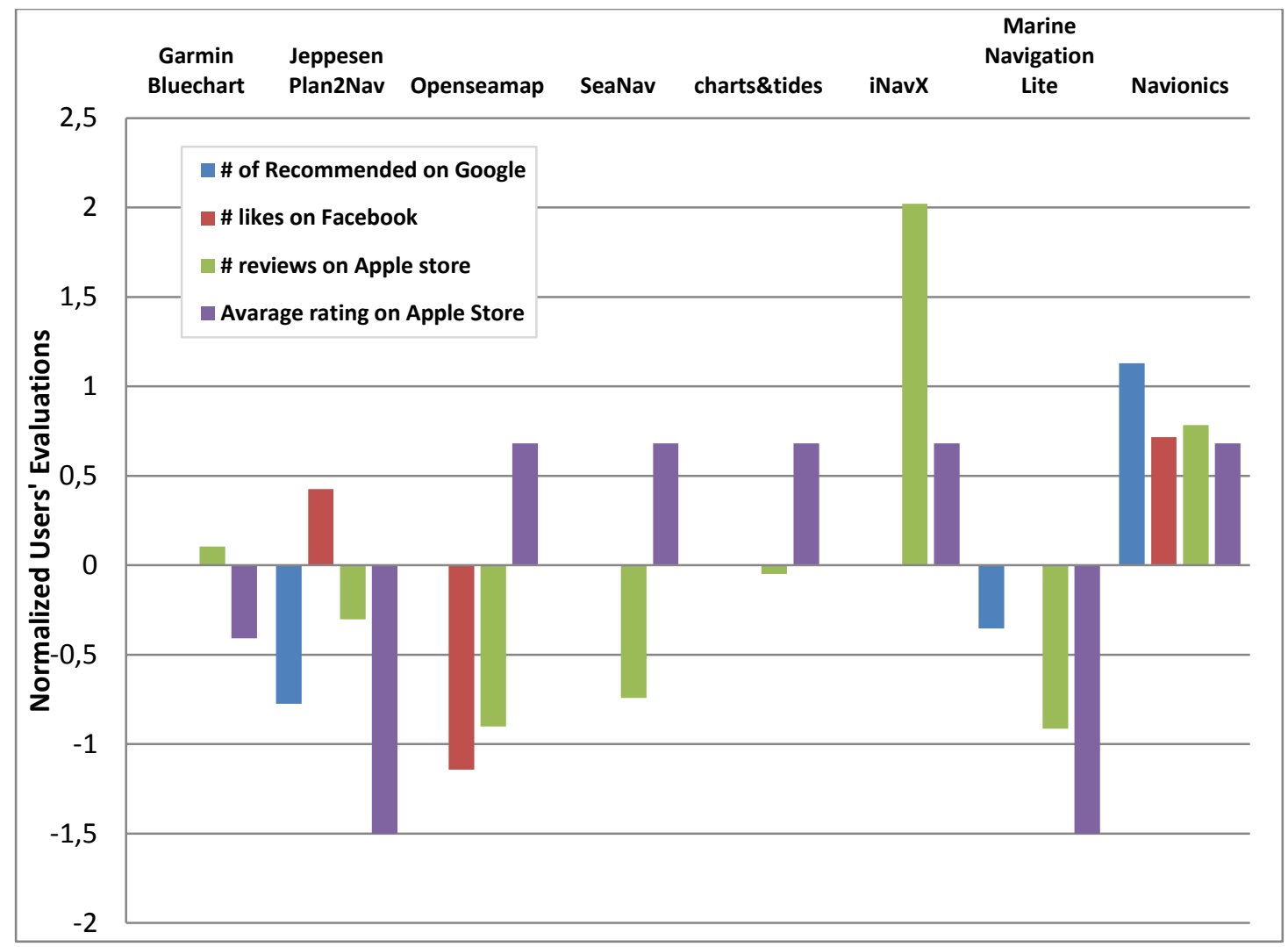

Figure 5: Users' evaluations of Marine Navigation Apps

As in in turn-by-turn competitive context, also marine navigation players approached market with different strategies. Table 3 shows the best adopter(s) for each strategy.

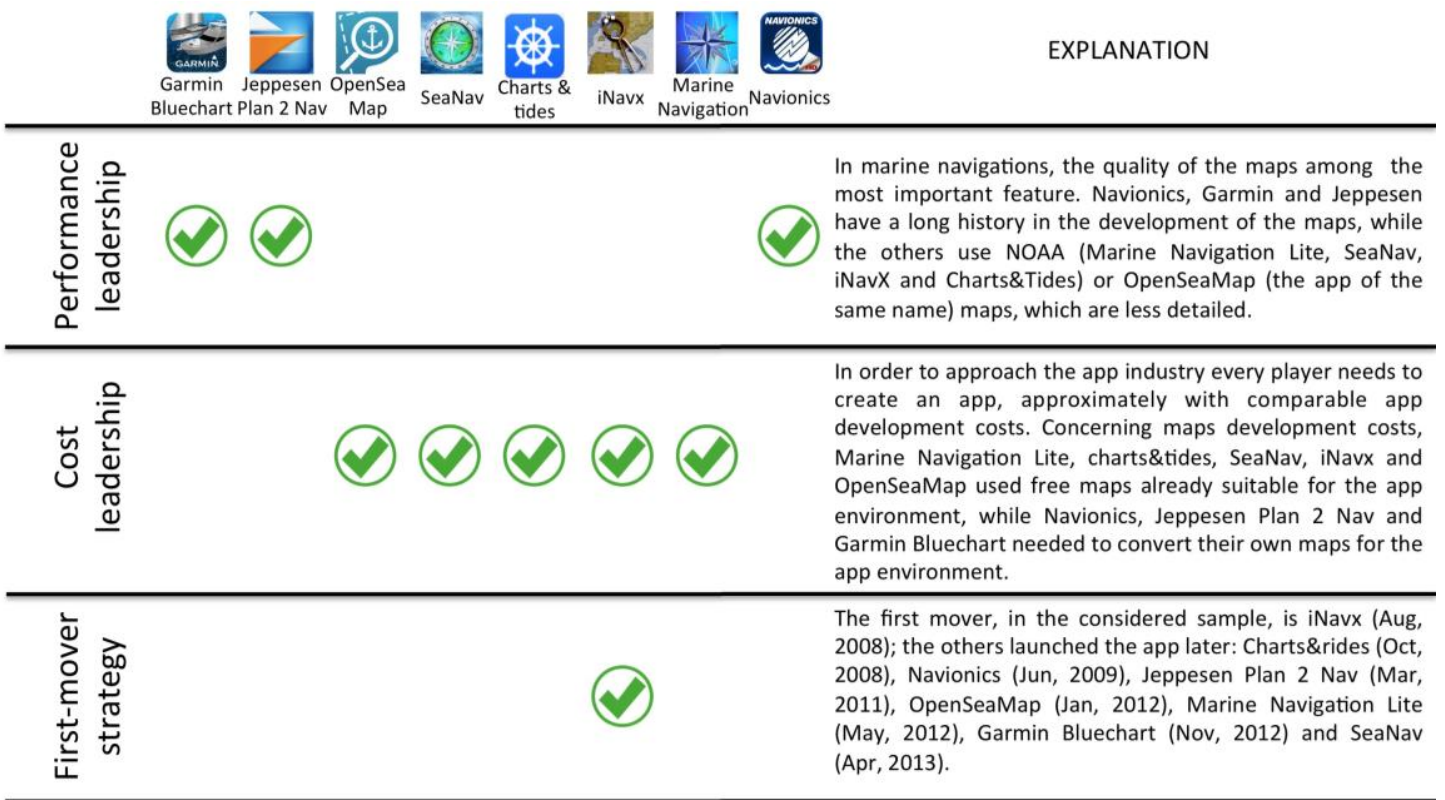

Table 3: Strategies in Marine Navigation Apps 
According to Table 3 both incumbents (Navionics, Jeppsen and Garmin) and new entrants (SeaNav, Charts \& tides, iNavx, Marine Navigation) successfully implemented at least one strategy. As a consequence Navionics success cannot be explained with traditional strategies because at least one competitor could be considered at par or better on each strategy. As in the previous case a technology epiphany is instead the key difference between Navionics and the competitors.

\subsection{Technology Epiphany: Navionics}

Building once again on Verganti (2009) we claim that the shift from chart-plotters to marine Apps on smartphones and tablets is mainly a technology substitution (see Figure 6). In addition to changing the device and adapting the technology, no breakthrough innovation was introduced. The Apps are cheaper but difficult to use and appear not to be able to fully compete with the traditional chart-plotters, because smartphones and tablets have less powerful antennas, depend on less durable batteries, and are not waterproof. Obviously it is possible to overcome these downsides using add-ons components, but the result is expensive and still not comparable with traditional chart-plotters. Navionics represents the only exception to this as they fully understood that boaters and sailors can use the App before and after the sea journey. They changed the why people use the App. 


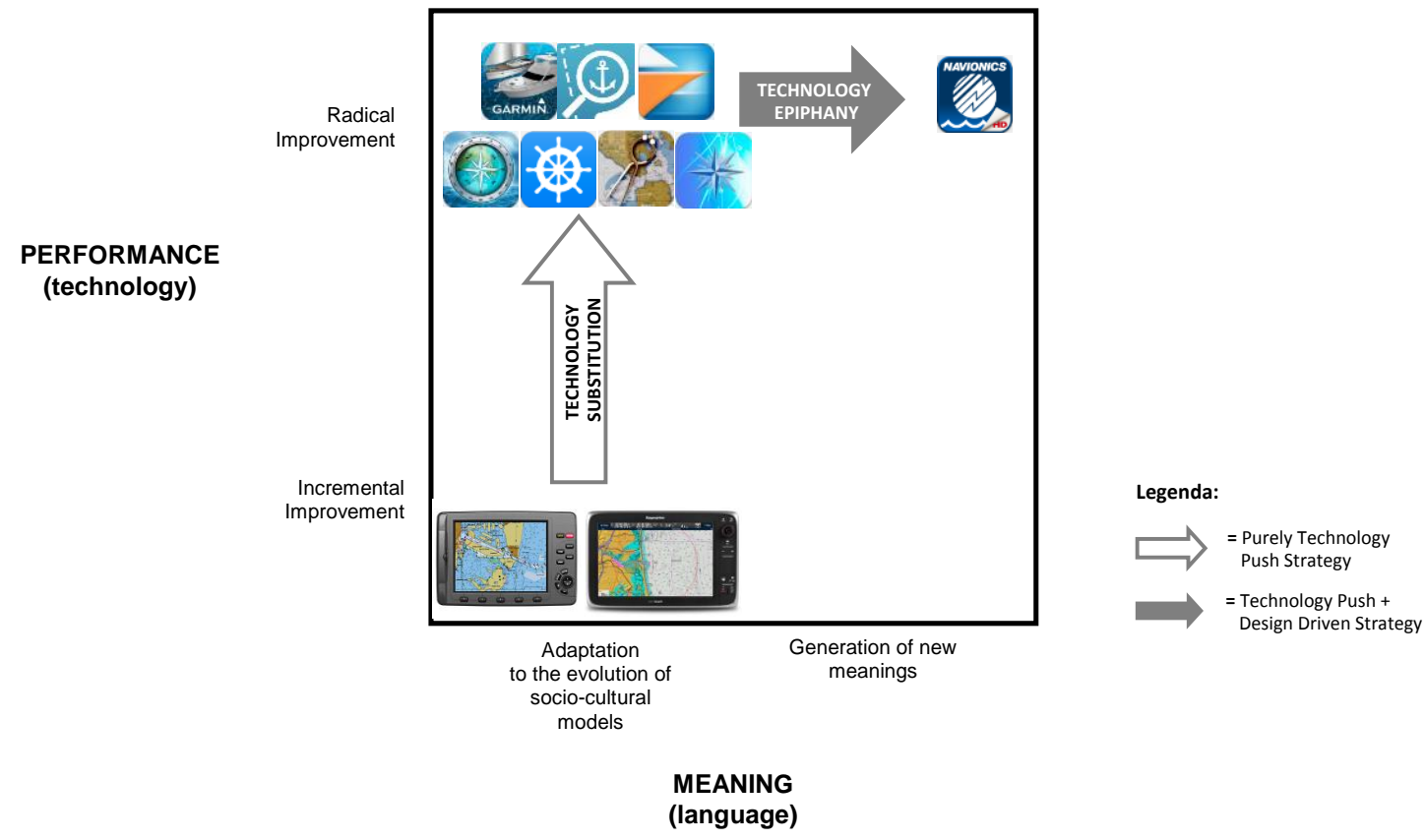

Figure 6: Technology substitution and Technology epiphany in Marine Navigation Industry

Since the beginning of the industry the main meaning of marine navigation has been unchanged; it was a tool to safely assist users while boating or sailing. This means that marine navigation systems were mainly used while actually boating and, even more precisely, when boating in specific areas (e.g., along the coast) or doing specific activities (e.g., following a route). This was the meaning for chart-plotters and does not seem to have changed in the marine navigation App we reviewed (Marine Navigation Lite, Charts\&Tides, SeaNav, iNavX, Openseamap, Jeppesen Plan2Nav, and Garmin Bluechart). Navionics changed this meaning by transforming the App into a tool to be used also before and after the nautical activity. The application is not meant to be a technological substitute for the traditional chart-plotter, but a complementary experience providing pre- and post-services to users. It even syncs with plotters to transfer markers and routes to the plotter at the beginning of the nautical activity and from the plotter at the end ${ }^{9}$.

Navionics did not leverage any particular new technology to achieve this change in meaning. They share with competitors all the hardware and software opportunities provided by smartphones and tablets. Nonetheless, they were able to see, before others, some 'hidden' opportunities already existing in those technologies.

${ }^{9}$ http://www.navionics.com/en/mobile-pc-app 


\subsection{Implementation Actions}

In order to make the new meaning actual, Navionics had to implement different actions. First of all they developed a community and a full set of features leveraging on it. The App, offers basic planning features as tracks or distances and advanced planning features such as autorouting, fishing modes, seabed composition and depth shading. Moreover, the community of boaters is heavily involved, providing fuel prices, personal experiences, updates of the marine $\mathrm{POI}$ database and geolocalized data to correct map errors. In this way the community constantly updates services and charts, and their quality is very much higher than before. For example, the Costa Concordia wreck was marked in just five hours; in the traditional business, nearly one year would have been necessary ${ }^{10}$. Navionics' App extends far beyond chartplotters, providing a full experience: planning, boating, and reviewing nautical activity.

In order to pursue the technology epiphany Navionics had to modify the dominant business model. Unlike the turn-by-turn navigation industry, the marine industry had a business model in which hardware (plotters) and contents (charts) were not provided by a single company ${ }^{11}$. Companies such as Navionics and Jeppesen focused their efforts on improving the quality of their maps in terms of details, coverage and precision. They did so by digitalizing map-related data and adding new information they generated through advanced remote sensing. Other companies (e.g., Raymarine, Navman, Lowrance, and Hummingbird) provided the hardware and the services for the final user. When smartphones and SDKs were released, Navionics attempted to replicate the business model by seeking third parties able to develop Apps delivering nautical services, with the intent of providing maps to the third parties as they did for the chart-plotters manufacturers. Navionics realized immediately that such providers were not on the market yet, thus they had to decide whether to wait for them or to drive the change in the market ${ }^{12}$. Navionics took the second option, switching their business model from map developers to nautical service developers. At the beginning, they provided different Apps according to the maps (e.g., US and Europe). The selling price was considerably lower than the one Navionics charged for traditional chart-plotter maps, as they understood that the market was not ready for very expensive Apps. Recently, Navionics realized that the App should be provided for free, allowing users to customize it through in-App purchases, in terms of maps but also in terms of services (e.g., auto-routing and sonar charts).

\footnotetext{
${ }^{10}$ Navionics CEO interview on March 13, 2014.

${ }^{11}$ As previously reported, Garmin previously integrated the two layers but recently modified their chart-plotters' design to work with Navionics and Jeppesen map.

12 Navionics CEO interview on March 13, 2014.
} 
The traditional marine navigator business was a seasonal one, linked to the fall nautical trade fairs where companies presented their new products. The seasonal business of chart-plotter manufacturers obviously influenced their providers markets and the map market was no exception, being seasonal as well. As explained in the turn-by-turn navigation case, the innovation speed in smartphones and tablet environments is a lot faster; instead of being yearly based, it is weekly based. For this reason, the 'waterfall' development model formerly used was no longer suitable, and Navionics had to change the development system speed to support its innovation in meaning. In Figure 7, it is possible to compare the average frequency of release of the different apps since the their first publication. To allow a deeper analysis, we first compared the general release frequency (any release is counted), then eliminated the releases that included only bug fixing and divided the remaining releases between improvement (e.g., improvement of existing features) and main improvement releases (e.g., complete new features or App redesign). Four researchers did independently the release coding, by classifying every release along the app history; data have been compared and averaged. No major differences are detectable among different players.

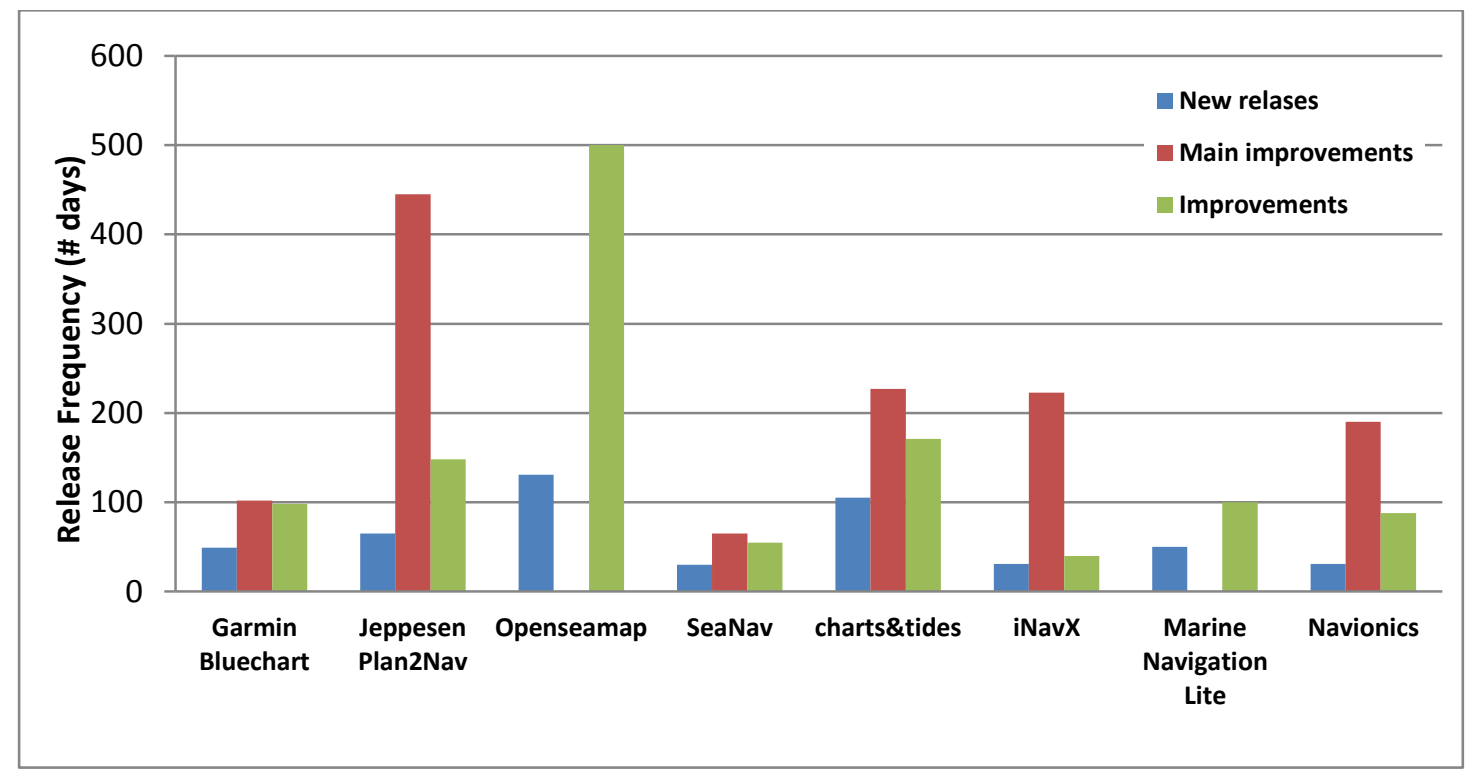

Figure 7: Release Frequency for Marine Navigation Apps

Finally, we can say that in order to implement the new meaning and get full advantage from the technology epiphany strategy Navionics had to i) develop a full set of features leveraging on the community, ii) challenge and adapt the dominant business model in the industry and iii) challenge and adapt the dominant development processes and practices in the industry. 


\section{CASE STUDIES COMPARISON}

Before comparing the data derived from the two case studies, it is important to underline how very different Navionics and Waze are. On the one hand, they share the same industry (Apps for smartphones/tablets) and even the same category (navigation); on the other hand, they differ in nearly all the other contingent variables. Waze is a start-up with no connections with companies in the turn-by-turn navigation market. Conversely, Navionics was a leader in the nautical map industry, which means they had a powerful brand (connected to the old meaning) and an incumbent position, which could allow them to be unprofitable at the beginning because they could finance the new initiative with the old, stable, and rentable market. Moreover, their competitive environments are very different. Turn-by-turn navigation systems are a quasi-commodity; almost everyone has one. The same cannot be said for marine navigation systems. Boats are definitely not a commodity and, even among boaters, these are a niche product still not affordable by everyone. In addition, the importance of map quality and competitive pressure is very different. Marine navigation maps are much more safety-critical than street maps. No one likes to have a missing road on the turn-by-turn navigation device, but, doubtless, finding a missing rock near the coast is another level of problem entirely. As a consequence, the importance of map quality acts as an entry barrier in the marine navigation business. Good and reliable maps crossing multiple data sources are a difficult asset to build.

Considering all these differences, it is even more surprising to note how the two companies adopted a similar managerial process to successfully implement their Technology Epiphany strategy (see Table 4). 


\begin{tabular}{|c|c|c|c|c|c|}
\hline & & \multicolumn{2}{|c|}{$\begin{array}{c}\text { TURN-BY TURN } \\
\text { NAVIGATION INDUSTRY }\end{array}$} & \multicolumn{2}{|c|}{$\begin{array}{c}\text { MARINE } \\
\text { NAVIGATION INDUSTRY } \\
\end{array}$} \\
\hline & & Traditional Business & WAZE & Traditional Business & NAVIONICS \\
\hline \multirow{5}{*}{ 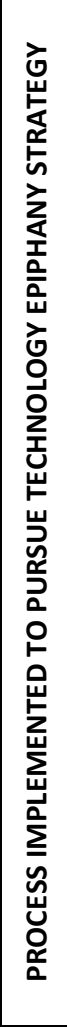 } & $\begin{array}{l}\text { Unveiling Opportunities } \\
\text { hidden in the technology }\end{array}$ & & $\begin{array}{l}\text { Smartphones and tablets are connected } \\
\text { to the Internet and are commonly } \\
\text { associated with community-based } \\
\text { services (e.g., Facebook, Twitter, } \\
\text { Whatsapp). }\end{array}$ & & $\begin{array}{l}\text { Smartphones and tablets are connected } \\
\text { to the internet and are commonly } \\
\text { associated with community-based } \\
\text { services (e.g., Facebook, Twitter, } \\
\text { Whatsapp). }\end{array}$ \\
\hline & $\begin{array}{l}\text { Translate the } \\
\text { opportunity into a } \\
\text { New Meaning }\end{array}$ & Drive the users to unknown places & $\begin{array}{l}\text { Get the best route, every day, with } \\
\text { real-time help from other drivers }\end{array}$ & $\begin{array}{l}\text { Assist the users during navigation by } \\
\text { providing detailed maps data }\end{array}$ & $\begin{array}{l}\text { Provide full support to boaters by } \\
\text { offering not only maps but also } \\
\text { community-based services before, } \\
\text { during, and after the nautical activity }\end{array}$ \\
\hline & $\begin{array}{l}\text { Develop new features to } \\
\text { reveal the new meaning }\end{array}$ & & $\begin{array}{l}\text { - Bypass traffic (based on users) } \\
\text { - Instant road alerts } \\
\text { - Gas prices } \\
\text { - PICK-UPS } \\
\text { - Meet-up } \\
\text { - Drive together } \\
\text { - Maps editing } \\
\text { - Social Media integration }\end{array}$ & & $\begin{array}{l}\text { - Crowdsourcing } \\
\text { - Marine POI } \\
\text { - Stories and Photo sharing } \\
\text { - Fuel prices } \\
\text { - Magazines and guides } \\
\text { - Social Media integration }\end{array}$ \\
\hline & $\begin{array}{l}\text { Adapt the business } \\
\text { model to the new } \\
\text { environment }\end{array}$ & $\begin{array}{l}\text { Design, manufacture, and sell both HW } \\
\text { and to provide a complete device }\end{array}$ & $\begin{array}{l}\text { Users already have the HW: } \\
\text { smartphones/tablets } \\
\text { - App for free } \\
\text { - Value created: community + new } \\
\text { services + fast updated maps } \\
\text { - Value appropriated: ads }\end{array}$ & $\begin{array}{l}\text { HW companies design, manufacture, } \\
\text { and sell chart-plotters, which can run } \\
\text { different maps } \\
\text { Map producers focus solely on map } \\
\text { quality }\end{array}$ & $\begin{array}{l}\text { Users already have the HW: } \\
\text { smartphones/ tablets } \\
\text { - App for free } \\
\text { - Value created: community + full } \\
\text { services + fast updated maps } \\
\text { - Value appropriated: selling maps + } \\
\text { advanced functionalities (in-App } \\
\text { purchasing) }\end{array}$ \\
\hline & $\begin{array}{c}\text { Adapt the development } \\
\text { processes to the new } \\
\text { environment }\end{array}$ & $\begin{array}{l}\text { New models almost every year } \\
\text { Maps updated quarterly }\end{array}$ & $\begin{array}{l}\text { - Speed } \\
\text { - High frequency releases (both maps } \\
\text { and functionalities) } \\
\text { - Agile development }\end{array}$ & $\begin{array}{l}\text { New models every year presented at } \\
\text { trade fairs } \\
\text { Maps updated quarterly }\end{array}$ & $\begin{array}{l}\text { - Speed } \\
\text { - High frequency releases (both maps } \\
\text { and functionalities) } \\
\text { - Agile development }\end{array}$ \\
\hline
\end{tabular}

Table 4: Comparison between Waze and Navionics case studies 
By comparing the two cases, it is possible to note how they changed 'why' people utilize their application by going through a similar sequence of steps.

First of all, both Waze and Navionics were able to "interpret" the smartphone not as a standard navigation tool (NPD or chart-plotter), but as a technology connected to the Internet and thus, natively enabling community-based services. Retrospectively, this might seem obvious; it is enough to check the App Store, and one discovers that many of the most widely distributed Apps are community-based and social (e.g., Facebook, Twitter, Whatsapp, etc.). Nonetheless, they were able to unveil this opportunity hidden in the technology before any other competitor in their industry.

Once the opportunity was detected, it was translated into a New Meaning. In the Waze case, the New Meaning was conceptualized as "Get the best route, every day, with real-time help from other drivers" against the old one dominating in the industry: "Drive the users to unknown places". Similarly in the Navionics case study, the New Meaning "Provide full support to boaters by offering not only maps but also community-based services before, during, and after the nautical activity" was conceptualized against the dominant one in the industry: "Assist the users during navigation by providing detailed maps data".

Both cases are then characterized by the development of new features able to reveal the New Meaning to the customers. In the Waze case study, we see the introduction of many functionalities leveraging the community and the real time bidirectional interconnection between its members and a central server: bypass traffic, instant road alerts, gas prices, etc. Similarly in the Navionics case study, new features leveraging the Internet connection and the community were introduced: crowdsourcing, marine POI, stories and photo sharing, etc.

It is interesting to note that in both case studies, the Technology Epiphanies requested the adaption of the Business Model and the Development Process to the new environment and that these adaptations appear to be very similar in the two case studies. In terms of business models, Waze and Navionics employ an already existing and widely distributed hardware (smartphones and tablets), distribute the app for free and generate value through communitybased features. Only in terms of value appropriation are the two case studies different: Navionics sell its content, whereas Waze leverages on advertising. However, considering the importance of map quality in the navigation industry (which means a lower number of comparable offers) and the very high price of the traditional solution (Chart-plotter + Maps), it is easy to understand why customers are willing to pay a medium-high price for Navionics' services. 
In addition, the two case studies demonstrate interesting similarities also in terms of development processes. Both cases exhibit superior development performances if compared with the traditional businesses. Marine and Turn-by-Turn traditional companies previously would release new products annually. On the contrary, new versions of the Apps are released every two weeks on average; they encompass significant improvements to existing functionalities quarterly and are completely revolutionized more than once a year. This development speed is even greater considering the maps: in the Waze case, they are updated daily. These performances are clear indicators of some agile development methodology typical of the smartphone app industry.

\section{DISCUSSION AND MANAGERIAL IMPLICATIONS}

Many academics focused so far on how to obtain value from a technological discontinuity. Many of the strategies proposed until now (like performance leadership, cost leadership, firstmover strategy, complementary assets management, influence on regulations and standards) have been studied in depth by previous research both in terms of definition and in terms of managerial practices to be implemented to pursue them.

By carefully design the research process and the case studies selection, we could find incredibly successful cases in which the effect of the abovementioned strategies could be considered negligible. Even if the adopted case study approach does not allow one to draw normative conclusions, the analysis of the collected data suggests that in competitive environments in which complementary assets and regulations/standards are not differentiating among players, the ability to develop Technology Epiphanies appears to outperform all other possible strategies such as performance leadership, cost leadership and first-moving strategies. Other researchers already focused on innovations able to suddenly annihilate incumbent companies and completely reshape the competitive environments (e.g., digital imaging and the film industry, or Amazon and booksellers). Downes and Nunes (2013) call them Big-Bang Disruptions and note that they appear to disobey the well-established strategic rules for innovation, 'Big-bang disrupters [...] are thoroughly un-disciplined. They start life with better performance at a lower price and greater customization. They compete with mainstream products on all three value disciplines right from the start' (p.8). Moreover, Big-Bang Innovations do not appear to respect the 'Rogers's classic bell curve of five distinct customer segments-innovators, early adopters, early majority, late majority, and laggards' 
(p.6), as they immediately target all segments of users. Finally, they seek innovation through rapid-fire, low-cost experimentation on popular platforms.

Our case studies perfectly fit this description.

Downes and Nunes recognize that the base for these innovations is not rooted in technology: 'in the future, the most successful innovators may be those who simply happen upon the right combination of other people's technologies' (p. 6). We claim that 'simply happen' must be somehow projectable. A possible way to achieve Big-Bang Disruptive innovations is to seek a Technology Epiphany. Unfortunately, though, this research field is still largely unexplored, as the phenomenon was identified and described in previous literature but no research has tried so far to shed some light on what process companies could employ to pursue a Technology Epiphany strategy. This article contributes in moving forward the boundaries of knowledge extracting a 5-step process from the two Technology Epiphany cases analysed (Figure 8).

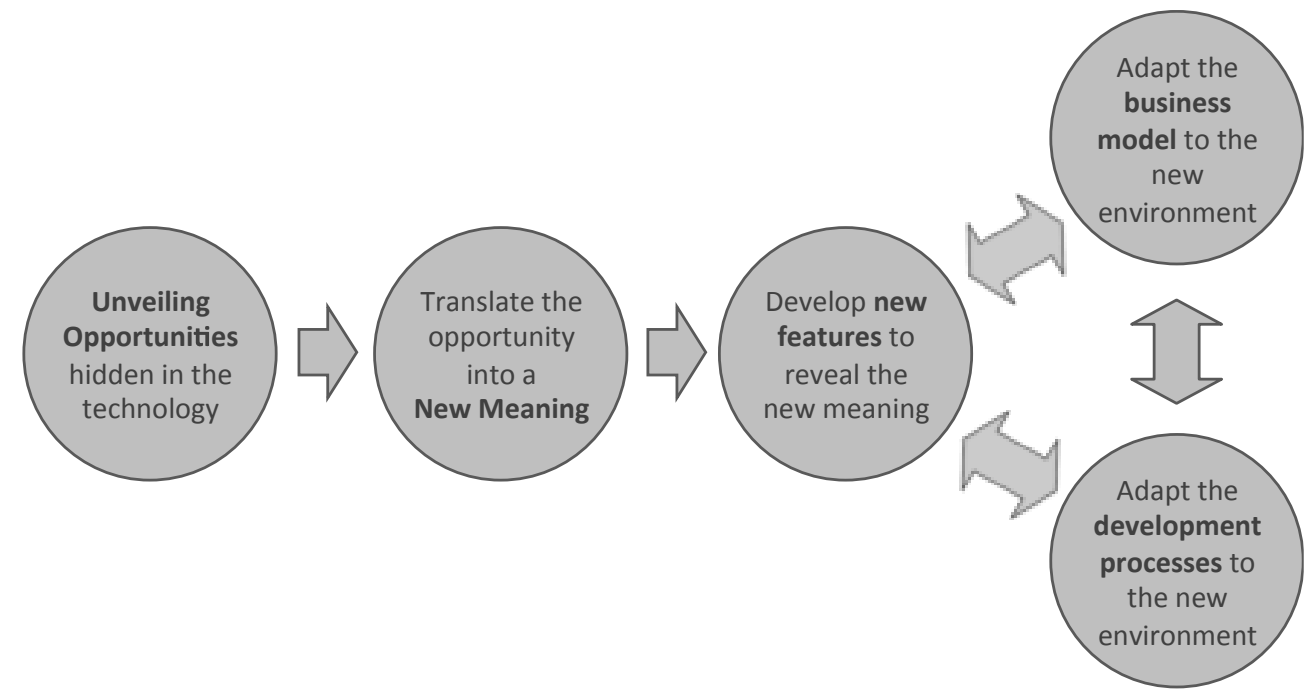

Figure 8: 5-steps process to implement Technology Epiphany strategies

The success in implementing a Technology Epiphany strategy appears to be connected to the following managerial steps:

\section{Step 1: Unveiling Opportunities hidden in the technology}

The first step is to understand what opportunities the technology provides. Looking at the technology in terms of existing features and performances will inevitably lead to a simple technology substitution (as in the case of TomTom) or to screen it off as not useful (as in the case of the Swiss manufacturers with the quartz mechanisms). Technologies have many hidden potential opportunities within them, and the first step is to make them appear (Proni, 2007). This first crucial step is very difficult and not surprisingly, it occurs sometime after the 
technological discontinuity. This dynamic is coherent with Abernathy and Utterback (1978) or Tushman and Anderson (1990): Technology Epiphanies do not come at the beginning of the ferment era. On the contrary, they come after a while and, retrospectively, they appear to have always been clearly written in the technology itself. Smartphones, unlikely chart plotters and Navigation Portable Devices, are communication tools (a telephone, a texter and an email client), and many of the top rated apps are social and community-based. It should be no surprise that smartphones provide the opportunity to leverage a community, as it should not be a surprise that LCDs brought calculators, meters and games into wristwatches. It is always easy to connect the dots backward.

\section{Step2: Translate the opportunity into a New Meaning}

The second step is to translate the opportunity into a New Meaning for the target industry. This second step requires, first of all, extensive knowledge of the market and of the current dominant meaning. It is not possible to assess the New Meaning as better or worse in comparison to the previous one; it is simply different (Verganti, 2009). Being significantly different, it requires new measures that cannot be compared with the previous one. Elaborating the new proposal on the "why" dimension instead of the "how" one, the New Meaning defines a new strategic direction to the point that sometimes, it can have the shape of a company mission as in the case of Waze: "provide the best route, every day, with realtime help from other drivers".

Step 3: Develop new features to reveal the New Meaning

The New Meaning creates no value if it remains potential. To make it actual, it is necessary to reveal it to customers through a whole set of features. These revealing features are all different ways to implement the meaning; each of them must be clearly and unequivocally connected to the New Meaning. For example, in the Waze case study, such features are bypass traffic (based on users), instant road alerts, meet-up, and maps editing, etc.

Steps 4 \& 5: Adapt the business model and the development process to the new environment The last two steps appear to be a needed but not sufficient prerequisite to pursue Technology Epiphanies. In an environment shaken by a technological discontinuity, the previous business models and development processes will hardly still be effective. Designing games for the Nintendo Wii must have required radical changes to the dominant developing process as well as the business models of quartz based watches being different form the traditional Swiss watch ones: quartz watches were not supposed to last forever. Similarly, both Waze and Navionics challenged the dominant business model in the industry (the apps are for free) as well as the development process (maps are now updated daily or weekly instead of quarterly 
or yearly). Comparing Waze and Navionics to their competitors, however, it is easy to see that many of them share similar business models and development strategies. These two managerial practices appear to be necessary enablers for developing a Technology Epiphany, but clearly not sufficient to effectively implement this strategy.

\section{LIMITATIONS AND POSSIBLE EVOLUTIONS}

The investigation leaves some relevant gaps. First, the sample is composed of only two case studies, and the exploratory nature of the research suggests the application of a literal replication in selecting them. On the one hand, more similar cases should be added to increase the internal validity of the results. On the other hand, it would be interesting to add new cases from outside navigation systems and perhaps, from outside the App industry, to increase the external validity as well. In terms of depth of the analysis, it would be very interesting to switch from secondary sources to primary sources, illuminating the internal organization of the analysed companies to provide an answer to some of the following questions: Is the probability for introducing Technology Epiphanies dependent on the internal skills of the development team? Is there a relationship between the development process and Technology Epiphanies? Are there other cases of Technology Epiphanies introduced by incumbent firms?

\section{REFERENCES}

- Abernathy WJ and Utterback JM (1978). Patterns of innovation in technology. Technology Review, Vol. 80, No. 7, Pp. 40-47.

- Abetti PA (1989). Technology: a Key Strategic Resource. Management Review, Vol. 78, No. 2, Pp. 37-41.

- Alvesson M, and Sandberg, J (2013). Constructing research questions: Doing interesting research. Sage.

- Baines TS, Lightfoot HW, Evans S, Neely A, Greenough R, Peppard J, ... and Wilson H (2007). State-of-the-art in product-service systems. Proceedings of the Institution of Mechanical Engineers, Part B: Journal of Engineering Manufacture, Vol. 221, No. 10, Pp. 1543-1552.

- Baldwin CY and Clark KB (2000). Design rules: The power of modularity (Vol. 1). MIT press. 
- Besen S, and Farrell J (1994). Choosing how to compete: Strategies and tactics in standardization. The Journal of Economic Perspectives, Pp. 117-131.

- Bresnahan T (1985). Post-entry competition in the plain paper copier market. The American Economic Review, Pp. 15-19.

- Bright A (1949). The electric-lamp industry. Macmillan.

- Bucher P. (2003). Integrated technology roadmapping: design and implementation for technology- based multinational enterprises, PhD Dissertation, ETH Zürich.

- Buganza T, Dell'Era C and Verganti R, (2009). Exploring the Relationships Between Product Development and Environmental Turbulence: The Case of Mobile TLC Services. Journal of Product Innovation Management; Vol. 26, Pp. 308-321

- Buganza T, Gerst M, and Verganti R (2010). Adoption of NPD flexibility practices in new technology-based firms. European Journal of Innovation Management, Vol. 13, No. 1, Pp. 62-80.

- Chiesa V and Manzini R (1998). Organizing for technological collaborations: a managerial perspective. R\&D Management, Vol. 28 No. 3, Pp. 199-212.

- Christensen CM (1997). The Innovator's Dilemma: When New Technologies Cause Great Firms to Fail. Boston: Harvard Business School Press.

- Christensen CM and Rosenbloom RS (1995). Explaining the attacker's advantage: technological paradigms, organizational dynamics, and the value network. Research Policy, Vol. 24, No. 2, Pp. 233-257.

- Cohen WM and Levinthal DA (1990). Absorptive capacity: a new perspective on learning and innovation. Administrative science quarterly, Pp. 128-152.

- Cooper RG (2005). Product leadership: Pathways to profitable innovation. Basic books.

- Cooper R and Slagmulder R, (1997). Target Costing and Value Engineering. Productivity Press, Oregon.

- Damania R and Fredriksson PG (2000). On the formation of industry lobby groups. Journal of Economic Behavior \& Organization, Vol. 41, No. 4, Pp. 315-335.

- David PA and Greenstein S (1990). The economics of compatibility standards: An introduction to recent research 1. Economics of innovation and new technology, Vol. 1, No. 1-2, Pp. 3-41.

- Dell'Era C, Marchesi A and Verganti R (2010). Mastering Technologies in design-driven innovation. Research-Technology Management, Vol. 53, No. 2, Pp. 12-23.

- Downes L and Nunes P (2013). The big idea: Big-bang disruption. Harvard Business Review (2013): 1-12. 
- Eisenhardt KM and Graebner ME (2007). Theory building from cases: opportunities and challenges. Academy of Management Journal, Vol. 50, No. 1, Pp. 25-32.

- Farrell J and Saloner G (1988). Coordination through committees and markets. The RAND Journal of Economics, Pp. 235-252.

- Farrell J and Saloner G (1992). Converters, compatibility, and the control of interfaces. The journal of industrial economics, Pp. 9-35.

- Foster RN (1986). Innovation: The attacker's advantage. New York: Summit Books.

- Frederickson JW (1984). The Comprehensiveness of Strategic Decision Process: Extension, Observations, and Future Directions. Academy of Management Journal, Vol. 27, Pp. 445-66.

- Ghemawat P (1984). Capacity expansion in the titanium dioxide industry. The Journal of Industrial Economics, Pp. 145-163.

- Gilbert RJ and Newbery DMG (1982). Preemptive patenting and the persistence of monopoly. American Economics Review, June 1982, pp. 514-526.

- Gopalarkrishna P and Subramanian R (2001). Revisiting the pure versus hybrid dilemma: Porter's generic strategies in a developing country. Journal of Global Marketing, Vol. 15 No. 2, Pp. 61-75.

- Grossman GM and Helpman E (1992). Protection for sale (No. w4149). National Bureau of Economic Research.

- Guan J and Zhao Q (2013). The impact of university-industry collaboration networks on innovation in nanobiopharmaceuticals. Technological Forecasting and Social Change, Vol. 80, No. 7, Pp. 1271-1286.

- Hill CWL (1988). Differentiation versus low cost or differentiation and low cost: a contingency framework. The Academy of Management Review, Vol. 13, Pp. 401-12.

- Hill CWL and Rothaermel FT (2003). The Performance of Incumbent Firms in the Face of Radical Technological Innovation. The Academy of Management Review, Vol. 28, No. 2, Pp. 257-274.

- Huff AS (1982). Industry influences on strategy reformulation. Strategic Management Journal, Vol. 3, No. 2, Pp. 119-131.

- lansiti M, McFarlan FW and Westerman G (2003). Leveraging the Incumbent's Advantage. MIT Sloan Management Review, Vol. 44, No. 4, Pp. 58-64.

- Ibusuki, U and Kaminski PC (2007). Product development process with focus on value engineering and target-costing: a case study in an automotive company. International Journal of Production Economics, Vol. 105, No. 2, Pp. 459-474. 
- Islas J (1999). The gas turbine: a new technological paradigm in electricity generation. Technological Forecasting and Social Change, Vol. 60 No. 2, Pp. 129-148.

- Judge WQ and Miller A (1991). Antecedents and Outcomes of Decision Speed in Different Environmental Contexts. Academy of Management Journal, Vol. 34, Pp. 449-63.

- Kalyanaram G, Robinson WT and Urban GL (1995). Order of Market Entry: Established Empirical Generalizations, Emerging Empirical Generalizations, and Future Research. Marketing Science, Vol. 14, Pp. G212-21.

- Kappel TA (1998). Technology roadmapping: an evaluation, Unpublished doctoral dissertation, Northwestern University.

- Lee H, Smith KG, Grimm CM and Schomburg A (2000). Timing, Order and Durability of New Product Advantages with Imitation, Strategic Management Journal, Vol. 21, Pp. 23-30.

- Lichtenthaler, E. (2004) Technology intelligence processes in leading European and North American multinationals. R\&D Management, Vol. 34, No. 2, pp.121-135.

- Lieberman MB and Montgomery DB (1988). First-mover advantages. Strategic management journal, Vol. 9, No. 1, Pp. 41-58.

- Lüthje C and Herstatt C (2004). The Lead User method: an outline of empirical findings and issues for future research. R\&D Management, Vol. 34, No. 5, Pp. 553-568.

- MacCormack A and lansiti M (2009). Intellectual Property, Architecture, and the Management of Technological Transitions: Evidence from Microsoft Corporation. Journal of Product Innovation Management, Vol. 26, No. 3, Pp. 248-263.

- MacCormack A, Verganti R and lansiti M (2001). Developing products on "Internet time": The anatomy of a flexible development process. Management science, Vol. 47, No. 1, Pp. 133-150.

- Main OW (1955). The Canadian nickel industry. University of Toronto Press: Toronto.

- Martino JP (1992). Probabilistic technological forecasting using precursor events. Technological Forecasting and Social Change, Vol. 42, Pp.121-131.

- McChrystal SA (2014). Operational Leadership. The RUSI Journal, Vol. 159, No. 2, Pp. 38-42.

- McKinsey Global Institute (2011). "Big Data: The next frontier for innovation, competition and productivity". 
- Miller R, Hobday M, Leroux-Demers T and Olleros X (1995). Innovation in complex systems industries: the case of flight simulation. Industrial and corporate change, Vol. 4 No. 2, Pp. 363-400.

- Mitchell W (1989). Whether and when? Probability and timing of incumbents' entry into emerging industrial subfields. Administrative Science Quarterly, Vol. 34, No. 2, Pp. 208-230.

- Mitchell W (1992). Are more good things better, or will technical and market capabilities conflict when a firm expands? Industrial and Corporate Change, Vol. 1, Pp. 327-346.

- Monden Y, 1995. Cost Reduction Systems: Target Costing and Kaizen Costing. Productivity Press, Oregon

- Murray Al (1988). A contingency view of Porter's "generic strategies". Academy of management review, Vol. 13, No. 3, Pp. 390-400.

- Neidrich WR and Swain SD (2003). The Influence of Pioneer Status and Experience Order on Consumer Brand Preference: a Mediated-effects Model. Journal of the Academy of Marketing Science, Vol. 31, Pp. 468-80.

- Nielsen (2013). "The Mobile Consumer - A Global Snaphot".

- Norman D and Verganti R (2014). Incremental and Radical Innovation: Design Research Vs. Technology and Meaning Change. Design Issues. Vol. 30, No. 1, Pp. 7896.

- Porter ME (1976). Interbrand choice, strategy, and bilateral market power (No. 146). Harvard University Press.

- Porter ME (1980). Competitive strategy: Techniques for analyzing industries and companies. New York.

- Porter ME (1985). Competitive Advantage. Free Press. ISBN 0-684-84146-0.

- Porter AL, Roper AT, Mason TW, Rossini FA, Banks J and Wiederholt BJ (1991). Forecasting and Management of Technology, John Wiley and Sons, New York.

- Prescott EC and Visscher M (1977). Sequential location among firms with foresight. The Bell Journal of Economics, Pp. 378-393.

- Proni G. (2007). Interview by author, Bologna, November 15.

- Ransley DL (1996). Benchmarking the 'external technology watching' process: Chevron's experience. Competitive Intelligence Review, Vol. 7, No. 3, Pp. 28-33. 
- Rao RC and Rutenberg DP (1979). Preempting an alert rival: Strategic timing of the first plant by analysis of sophisticated rivalry. The Bell Journal of Economics, Pp. 412428.

- Robinson WT, Fornell C and Sullivan M (1992). Are Market Pioneers Intrinsically Stronger than Later Entrants?. Strategic Management Journal, Vol. 13, Pp. 609-24.

- Rosenkopf L and Nerkar A (1999). On the Complexity of Technological Evolution: Exploring Coevolution Within and Across Hierarchical Levels in Optical Disc Technology. Variations in Organization Science: In Honor of D. T. Campbell, Sage Publications.

- Rothaermel FT (2001b). Incumbent's advantage through exploiting complementary assets via interfirm cooperation. Strategic Management Journal, Vol. 22, No. 6-7, Pp. 687-699.

- Rothaermel, F. T. (2001a). Complementary assets, strategic alliances, and the incumbent's advantage: an empirical study of industry and firm effects in the biopharmaceutical industry. Research Policy, Vol. 30, No. 8, Pp. 1235-1251.

- Sanchez R and Mahoney JT (1996). Modularity, flexibility, and knowledge management in product and organization design. Strategic management journal, Vol. 17, No. S2, Pp. 63-76.

- Schmalensee R (1978). Entry deterrence in the ready-to-eat breakfast cereal industry. The Bell Journal of Economics, Pp. 305-327.

- Schmalensee R (1981). Economics of scale and barriers to entry. Journal of Political Economy, pp. 1228-1238.

- Seidenschwarz, W. (2003). Target costing (pp. 437-453). Gabler Verlag.

- Shaw RW and Shaw SA (1984). Late entry, market shares and competitive survival: the case of synthetic fibers. Managerial and Decision Economics, Vol. 5, No. 2, Pp. 72-79.

- Simoni M, Cautela C and Zurlo F (2014). Product design strategies in technological shifts: An explorative study of Italian design-driven companies. Technovation, Vol. 34, Pp. 702-715.

- Spence AM (1981). The learning curve and competition. The Bell Journal of Economics, Vol. 12, No. 1, Pp. 49-70.

- Teece DJ (1986). Profiting from technological innovation: implications for integration, collaboration, licensing and public policy. Research Policy, Vol. 15, Pp. 285-305. 
- Teece DJ (1998). Capturing Value from Knowledge Assets: The New Economy, Markets for Know-How and Intangible Assets. California Management Review, Vol. 40, No. 3, Pp. 55-79.

- Tempelman E, Kandachar PV, Spitas C and Vergeest JSM (2012). Technology transformation as a new paradigm for design engineering research, in the Proceedings of the 2012 TMCE Conference, Karlsruhe, Germany, May 7-12 2012.

- Treacy M and Wiersema F (1997). Discipline of Market Leaders: Choose your customers, narrow your focus, dominate your market. Basic Books.

- Tripsas M (1997). Unraveling the process of creative destruction: complementary assets and incumbent survival in the typesetter industry. Strategic Management Journal, Vol. 18 (Summer Special Issue), Pp. 119-142.

- Tripsas M and Gavetti G (2000). Capabilities, Cognition, and Inertia: Evidence from Digital Imaging. Strategic Management Journal, Vol. 21, No. 10-11, Pp. 1147-1161.

- Tushman ML and Anderson P (1986). Technological Discontinuities and Organizational Environments. Administrative Science Quarterly, Vol. 31, No. 3, Pp. 439-465.

- Tushman ML and Anderson P (1990). Technological Discontinuities and Dominant Designs: A Cyclical Model of Technological Change. Administrative Science Quarterly, Vol. 35, No. 4, Pp. 604-633.

- Tushman ML and Anderson P (2004). Managing Strategic Innovation and Change. 2nd edition, Oxford University Press.

- Urban GL and Von Hippel E (1988). Lead user analyses for the development of new industrial products. Management science, Vol. 34, No. 5, Pp. 569-582.

- Utterback JM (1994). Mastering the Dynamics of Innovation, Harvard Business Press, Boston, MA.

- Valentine-Urbschat M and Bernhart W (2008). Powetrain 2020 - Challenges and opportunities for OEMs and Suppliers. EVS25, Stavanger.

- Vandermerwe S and Rada J (1989). Servitization of business: adding value by adding services. European Management Journal, Vol. 6, No. 4, Pp. 314-324.

- VanderWerf PA and Mahon JF (1997). Meta- analysis of the Impact of Research Methods on Findings of First-mover Advantage. Management Science, Vol. 43, Pp. 1510-19.

- Verganti R (2009). Design-Driven Innovation. Changing the Rules of Competition by Radically Innovating What Things Mean. Harvard Business Press, Boston. 
- Verganti R (2011a). Radical Design and Technology Epiphanies: A New Focus for Research on Design Management. Journal of Product Innovation Management, Vol. 28, Pp. 384-388.

- Verganti R (2011b). Designing Breakthrough Products. Harvard Business Review, October, 2011.

- Von Hippel E (1986). Lead users: a source of novel product concepts. Management science, Vol. 32, No. 7, Pp. 791-805.

- Weiss M and Cargill C (1992). Consortia in the standards development process. Journal of the American Society for Information Science (1986-1998), Vol. 43, No. 8.

- Wernerfelt B (1985). Brand loyalty and user skills. Journal of Economic Behavior \& Organization, Vol. 6, No. 4, Pp. 381-385.

- Worren N, Moore K and Cardona P (2002). Modularity, strategic flexibility, and firm performance: a study of the home appliance industry. Strategic management journal, Vol. 23, No. 12, Pp. 1123-1140.

- Yin RK (1984). Case Study Research, Design and Methods. London: Sage Publications.

- Yin RK (2013). Case study research: Design and methods. Sage publications.

- Zahra SA and George G (2022). Absorptive capacity: A review, reconceptualization and extension. Academy of management review, Vol. 27, No. 2, Pp. 185-203. 